\title{
Microvasculopathy, Luminal Calcification and Premature Aging in Fetuin-A Deficient Mice
}

Marietta Herrmann ${ }^{1,6^{*}}$, Anne Babler $^{1^{*}}$, Irina Moshkova ${ }^{1}$, Felix Gremse ${ }^{2}$, Fabian Kiessling ${ }^{2}$, Ulrike Kusebauch ${ }^{3}$, Valentin Nelea ${ }^{4}$, Rafael Kramann ${ }^{5}$, Robert L. Moritz ${ }^{3}$, Marc D. McKee ${ }^{4}$, Willi Jahnen-Dechent ${ }^{1}$

${ }^{1}$ Helmholtz Institute for Biomedical Engineering, Biointerface Lab, RWTH Aachen University Hospital, Aachen, Germany

${ }^{2}$ Helmholtz Institute for Biomedical Engineering, Experimental Molecular Imaging, RWTH Aachen University Hospital, Aachen, Germany

${ }^{3}$ Institute for Systems Biology, Seattle, WA, USA

${ }^{4}$ Faculty of Dentistry, Faculty of Medicine (Dept. of Anatomy and Cell Biology), McGill

University, Montreal, Quebec, Canada

${ }^{5}$ Division of Nephrology, RWTH Aachen University Hospital, Aachen, Germany

${ }^{6}$ current affiliation: IZKF Group Tissue Regeneration in Musculoskeletal Diseases, University Clinics and Orthopedic Center for Musculoskeletal Research, University of Wuerzburg, Wuerzburg, Germany

*equal contribution

Running title: Fetuin-A Deficiency, Ectopic Mineralization and premature aging Co-corresponding authors:

Prof. W. Jahnen-Dechent, Helmholtz Institute for Biomedical Engineering, Biointerface Laboratory, RWTH Aachen University Hospital, Pauwelsstrasse 30, 52074 Aachen, Germany, Phone: +49-241-8080163, Fax: +49-241-8082573, E-mail: willi.jahnen@rwthaachen.de

Prof. M.D. McKee, McGill University, Montreal, Quebec, Canada H4A 0C7 Phone +1-514398-7203 ext. 00041, Fax+1-514-398-8900, E-mail: marc.mckee@mcgill.ca

Keywords - calcification, calciprotein particles, mineral metabolism, fetuin-A, mouse models

Subject Codes - Animal Models of Human Disease, Fibrosis, Inflammation, Proteomics, Peripheral Vascular Disease

Word count - 6019 (excl. References and Figure Legends)

Total number of figures and tables - 8 figures, 6 tables, 3 supplement figures, 6 movies

The author version of this manuscript was deposited at BioRxiv.org [1]. 


\begin{abstract}
Objective - The plasma protein fetuin-A mediates the formation of protein-mineral colloids known as calciprotein particles (CPP) - rapid clearance of these CPP by the reticuloendothelial system prevents errant mineral precipitation and therefore ectopic mineralization (calcification). The mutant mouse strain D2,Ahsg-/- combines fetuin-A deficiency with the mineralization-prone DBA/2 genetic background, having a particularly severe compound phenotype of microvascular and soft tissue mineralization. Here we studied mechanisms leading to soft tissue mineralization, organ damage and premature aging in these mice.
\end{abstract}

Approach and Results - We analyzed mice longitudinally by echocardiography, X-raycomputed tomography, analytical electron microscopy, histology, mass spectrometry proteomics, and genome-wide microarray-based expression analyses of D2 wildtype and Ahsg-/-mice.

Fetuin-A deficient mice had calcified lesions in myocardium, lung, brown adipose tissue, reproductive organs, spleen, pancreas, kidney and the skin, associated with reduced growth, cardiac output and premature aging. Importantly, early stage calcified lesions presented in the lumen of the microvasculature suggesting precipitation of mineral containing complexes from the fluid phase of blood. Genome-wide expression analysis of calcified lesions and surrounding (not calcified) tissue, together with morphological observations, indicated that the ectopic mineralization was not associated with osteochondrogenic cell differentiation, but rather with thrombosis and fibrosis.

Conclusions - Collectively, these results demonstrate that pathological mineralization can start by intravascular mineral deposition causing microvasculopathy, which impacts on growth, organ function and survival. Our study underscores the importance of fetuin-A and related systemic regulators of mineralized matrix metabolism to prevent cardiovascular disease, especially in dysregulated mineral homeostasis. 


\section{Introduction}

High concentrations of extracellular phosphate are toxic to cells. Impaired urinary phosphate excretion increases serum phosphate level and induces a premature-aging phenotype. Patients suffering from chronic kidney disease (CKD), especially patients on dialysis have increased serum phosphate and associated high cardiovascular morbidity and mortality [2]. Recently we showed that the phosphate toxicity may in fact be caused by the uptake and inflammatory action of excess protein-mineral complexes called calciprotein particles, CPP [3]. These particles form in supersaturated calcium and phosphate solutions (with respect to hydroxyapatite) also containing plasma proteins, chief among which it the hepatic glycoprotein fetuin-A. The cellular clearance and biological activity of CPP depend on their maturation state and crystallinity. The particles undergo a typical two-stage ripening process, starting as spherical primary CPP measuring 50-150 nm in diameter, which are chemically unstable, contain amorphous mineral, and are preferentially cleared by endothelial cells [3]. Primary CPP spontaneously transform into oblongate secondary CPP ranging up to $500 \mathrm{~nm}$ in length; these are stable for at least $24 \mathrm{~h}$ at body temperature [4], they contain crystalline mineral and are therefore more rigid, and are preferentially cleared by macrophages of the mononuclear phagocytic system [5]. Colloidal CPP allow efficient transport and protected clearance of bulk mineral without risk of precipitation. However fetuin-A is critically required to form stable CPP, and fetuin-A deficient CPP are unstable and readily precipitate [6]. Like lipoproteins play a critical role in lipid transport and metabolism, fetuin-A plays a critical role in solubilization and clearance from the circulation of calcium phosphate-protein complexes. In line with this, several studies have identified protein-mineral particles containing fetuin- $A$ in granules formed by incubation of serum-containing cell culture media with calcium and phosphate [7], in the serum of bisphosphonate (etridronate)-treated rats [8], and in an animal model of renal failure [9]. Furthermore, the accumulation of fetuin-A-containing mineral particles was noted in the peritoneal dialysate of a patient suffering from calcifying peritonitis [10] and in patients suffering from chronic kidney disease (CKD) [11]. Recent work has shown that both the abundance of CPP [12-14] and the kinetics of CPP formation [15-18] in serum of CKD patients can be used to monitor the calcification propensity of these patients. The function of fetuin- $A$ as an inhibitor of ectopic mineralization is underscored by clinical studies showing that low fetuin-A serum levels are associated with calcification disease [1925].

Over some years now, we have generated fetuin-A deficient $A h s g-/-$ mice and backcrossed them onto two defined genetic backgrounds, C57BL/6 (B6) and DBA/2 (D2) [26, 27]. DBA/2 mice, like $\mathrm{C} 3 \mathrm{H}, \mathrm{C} 3 \mathrm{Hf}$ and $\mathrm{BALB} / \mathrm{c}$ mice, are prone to dystrophic cardiac calcification [27, 28], while C57BL/6 mice are relatively calcification-resistant. D2,Ahsg-/- mice are certainly one of the most calcification-susceptible mouse strains known [29]. Concurrently with this work we established that the calcification phenotype of D2,Ahsg-/- mice is governed by combined deficiency of fetuin-A, pyrophosphate and magnesium, thus affecting three potent extracellular regulators of mineralization at once [30]. This prominent calcification phenotype is not surprisingly associated with bone abnormalities [31], decreased breeding performance, organ damage, and increased mortality. For example, severe renal calcinosis ultimately causes secondary hyperparathyroidism [29], and myocardial mineralization is associated with fibrosis and diastolic dysfunction [32]. Despite the fact that D2,Ahsg-/- mice have one of the most severe phenotypes of ectopic mineralization, the early events leading to this are poorly understood, because once started, mineralization proceeds extremely rapidly. Here, in 
the present study, we performed a detailed analysis of progressive worsening of the soft tissue mineralization in D2,Ahsg-/- mice applying the techniques of computed tomography, histology, electron microscopy, genetic and proteomic analysis. We report that mineralized lesions first develop in these mice within the lumen of microvessels, indicating that mineralization in these mice is caused primarily by disturbed mineral ion handling in the extracellular fluids including blood. One early consequence of disturbed mineral matrix metabolism is myocardial calcification and dysfunction, which progressively worsens and is primarily responsible for premature death in D2,Ahsg-/- mice. These mice are well suited to study the cardiovascular consequences of dysregulated mineral homeostasis, a hallmark feature of chronic kidney disease CKD in the aging population, even more exacerbating calcification and premature aging in affected children [33]. Unlike other models of CKDassociated cardiovascular disease CVD or of premature aging, D2,Ahsg-/- mice require no special diet or surgical intervention. They progressively develop CVD allowing therapeutic intervention, and the detailed study of calcification associated CVD including novel therapeutic intervention strategies. 


\title{
Material and Methods
}

\author{
Animals \\ Wildtype and fetuin-A-deficient mice on either the DBA/2N or C57BL/6N genetic background \\ were maintained in a temperature-controlled room on a 12-hour light/dark cycle. Standard \\ diet (Ssniff, Soest, Germany) and water were given ad libitum. Mice were kept at the animal \\ facility of RWTH Aachen University Clinics. All animal experiments were conducted in \\ agreement with German animal protection law and were approved by the state animal \\ welfare committee.
}

At different ages (as indicated in the figures), mice were sacrificed with an overdose of isoflurane and exsanguinated. Animals were perfused with $20 \mathrm{ml}$ ice-cold PBS to rinse blood from the circulation unless otherwise stated.

\section{Computed tomography (whole mice)}

Mice were anaesthetized with isoflurane and placed in a high-resolution computer tomograph (Tomoscope DUO, CT-Imaging, Erlangen, Germany). The settings of the CT scan were: 65 $\mathrm{kV} / 0.5 \mathrm{~mA}$, and 720 projections were acquired over 90 seconds each. Analysis of the CT scans was performed with the Imalytics Preclinical Software [34]. Full-body acquisitions were obtained to examine in three dimensions the overall state of mineralization in the mice.

\section{Micro-computed tomography (mouse organs)}

Micro-computed tomography (Micro-CT, model 1072; Skyscan, Kontich, Belgium) of heart, lung, kidney, testis, skin, spleen and pancreas was performed to visualize entire mineralization patterns in three dimensions and at higher resolution within various selected organs. The X-ray source was operated at a power of 40-50 kV and at 200-250 $\mu \mathrm{A}$. Images were captured using a 12-bit, cooled, charge-coupled device camera (1024 x 1024 pixels) coupled to a fiber optic taper to the scintillator. Using a rotation step of $0.9^{\circ}$, each sample was rotated through 180 degrees with a scan resolution of 10-18 microns per pixel. Data was processed and reconstructed using Skyscan tomography software TomoNT (ver. 3N.5), CT Analyser (CTAn ver. 1.10.0.2 and CT Volume (CTVol ver. 2.0.1.3).

\section{Histology and immunohistochemistry}

For light microscope histology, organs were collected without perfusion and with immersion fixation in paraformaldehyde for at least $24 \mathrm{~h}$. The fixed samples were subsequently dehydrated and embedded in paraffin. Hematoxylin/eosin and von Kossa staining was performed on 5 - $\mu \mathrm{m}$-thick sections. For immunohistochemical staining visualized by immunofluorescence microscopy, freshly dissected (unfixed) tissues were embedded in Tissue-Tek embedding medium (Sakura Finetek, Staufen, Germany), frozen in liquid nitrogen, and then kept at $-20^{\circ} \mathrm{C}$ until use. Cryosections were cut at 6 - $\mu \mathrm{m}$-thick followed by fixation with Bouin's fixative. Mineralized tissue was decalcified with 0.5 M EDTA overnight. PBS-washed sections were blocked with $5 \%$ goat serum (Dako, Hamburg, Germany) prior to primary antibody incubation. Primary antibodies were rat anti-mouse CD31 (BD Pharmingen, Franklin Lakes, NJ, USA, dilution 1:10), rabbit anti-mouse OPN (R\&D Systems, McKinley Place NE, MN, USA, dilution 1:1000), rat anti-mouse OPN (Enzo Life Science, Lörrach, Germany, dilution 1:100) and rabbit anti-mouse Lyve-1 (Acris Antibodies GmbH, Herford, 
Germany, dilution 1:1000); all incubated for 1 hour. Primary antibodies were detected by secondary antibodies coupled with either Alexa Fluor 488 or Alexa Fluor 546 (all Molecular Probes, Life Technologies, Carlsbad, CA, USA). DAPI (Sigma, Taufkirchen, Germany) was used as a nuclear stain. Stained sections were examined with a Leica DMRX fluorescence microscope (Leica Microsystems $\mathrm{GmbH}$, Wetzlar, Germany) and DISKUS software (Carl H. Hilgers, Technisches Büro, Königswinter, Germany). Pictures were processed with Adobe Photoshop (Adobe Systems $\mathrm{GmbH}$, München, Germany).

To detect early-stage calcified lesions, bovine fetuin-A (Sigma) was purified by gel filtration, and $100 \mu \mathrm{l}$ of a $7 \mathrm{mg} / \mathrm{ml}$ protein solution was injected intraperitoneally one day before euthanasia. Fetuin-A was detected on cryosections using a rabbit polyclonal anti-fetuin-A antibody (AS 237) made in-house, followed by secondary Alexa Fluor 546 goat anti-rabbit antibody.

\section{Electron microscopy}

For ultrastructural characterization by transmission electron microscopy (TEM), interscapular brown adipose tissue sections were fixed with $2 \%$ glutaraldehyde (Electron Microscopy Sciences, Hatfield, PA, USA) and dehydrated through a series of graded ethanol dilutions. Samples were embedded in LR White acrylic resin or epoxy resin (Electron Microscopy Sciences). Ultrathin sections (80-nm-thick) cut with a Leica EM UC6 ultramicrotome (Leica Microsystems Canada, Ltd, Richmond Hill, ON) were placed on formvar-coated nickel grids (Electron Microscopy Sciences) and stained (or left unstained) with uranyl acetate and lead citrate (Electron Microscopy Sciences) for viewing by TEM. A field-emission FEI Tecnai 12 BioTwin TEM (FEl, Hillsboro, OR, USA) was used to image the stained sections at $120 \mathrm{kV}$.

Electron diffraction in the selected-area configuration (SAED), and energy-dispersive X-ray spectroscopy (EDS) were performed on unstained sections at $200 \mathrm{kV}$ using a Philips CM200 TEM equipped with a Gatan Ultrascan 1000 2k X 2 k CCD camera system model 895 and an EDAX Genesis EDS analysis system (FEI, Hillsboro, OR, USA).

\section{X-ray diffraction}

X-ray diffraction (XRD) analysis was performed using a D8 Discover diffractometer (BrukerAXS Inc., Madison, WI, USA) equipped with a copper X-ray tube (wavelength, $1.54056 \AA$ ), and a HI-STAR general area detector diffraction system (Bruker-AXS Inc.). All components (X-ray source, sample stage, laser/video alignment/monitoring system and detector) are mounted on a vertical $\theta-\theta$ goniometer. Measurements were run in coupled $\theta-\theta$ scan in microbeam analysis mode (50 $\mu \mathrm{m} \mathrm{X}$-ray beam spot size). Samples used were tissueembedded LR White acrylic blocks (the same block faces used for preparing the optical and electron microscopy sections) for small-area, localized analyses of mineral-rich regions identified on the block face.

\section{Gene expression analysis}

Wildtype and Ahsg-/- DBA/2 mice at 6-7 weeks of age were used for gene expression analysis, using 2-3 female and 2-3 male mice. Kidneys and brown adipose tissue dissected from the kidney pelvic region were collected. Tissue samples were homogenized and stored in peqGOLD RNAPure reagent (PEQLAB Biotechnologie GMBH, Erlangen, Germany). RNA extraction was performed using a standard phenol-chloroform extraction procedure or RNeasy Lipid Tissue Mini Kit (Qiagen, Hilden, Germany), respectively. The gene expression 
profile was analyzed with Affymetrix Mouse Genome 4302.0 Arrays (Affymetrix, Santa Clara, CA, USA). Gene data analysis was carried out using Bioconductor [35] packages under R1. The quality of microarrays was assessed using the ArrayQualityMetrics package [36]. The arrays were analyzed with the outlier detection algorithm within the package. Arrays with two or more outlier calls were considered of insufficient quality, and these were excluded from further normalization and data analysis. Background adjustment, normalization and summarization were applied using the RMA algorithm within the Affy package [35, 37]. Probe sets which could not be annotated to any gene, were removed from the expression set. A mean standard deviation of all probe sets was calculated. All probe sets which had a lower standard deviation than the mean standard deviation were excluded. Both filtering methods were performed using the Genefilter package [38]. Differential expression was probed using Bayesian statistics and Limma package [35]. Differences between genotype and sex, as well as a possible interaction of both, were calculated. Multiple testing correction was performed using the procedure of Benjamini Hochberg implemented in the Multtest package [39]. Probe sets with a p-value below 0.05 were considered as differentially expressed. Annotation of probe sets was applied with Annaffy, Annotate and Mouse4302.db packages [40-42]. Volcano plot representation was used to visualize differential expression. Differential expressed probe sets were tested for overrepresentation of KEGG gene sets. The analysis was performed using the GSEABase package [43] under Bioconductor.

\section{Protein analysis}

Interscapular brown adipose tissue, skin (interscapular region) and heart were dissected. Mineralized lesions were scraped out under a dissection microscope (Leica MZ6). Mineralization-free tissue was collected as control tissue. Samples were frozen in liquid nitrogen and stored at $-70{ }^{\circ} \mathrm{C}$. Samples were thawed, transferred to $2 \mathrm{~mL}$ reaction tubes, and incubated with SDS sample buffer (0.25 M TRIS, $8.2 \%$ SDS, $20 \%$ glycerin, $10 \% \beta$ mercaptoethanol, bromophenol blue) containing $40 \mathrm{mM}$ EDTA at $96{ }^{\circ} \mathrm{C}$ for $5 \mathrm{~min}$ at $10 \mu \mathrm{l}$ per $1 \mathrm{mg}$ tissue. The supernatant was removed, and tissue pellets were homogenized for $2.5 \mathrm{~min}$ at $25 \mathrm{~Hz}$ in a mixer mill (Tissue Lyser II, Qiagen, Hilden, Germany). Following this, samples were boiled for 5 minutes. Protein extracts were separated in $12.5 \%$ polyacrylamide gels using SDS-PAGE. Gels were washed and proteins were stained with Imperial Protein Stain (Thermo Fisher Scientific, Rockford, IL, USA) for 2 hours. Unbound stain was removed by washing in ultra-pure water over night. Pictures of gels were recorded using a digital camera. Gel lanes were cut into 2-mm bands using a GridCutter (The Gel Company, San Francisco, USA). Individual gel slices were subjected to in-gel reduction with dithiothreitol (10 mM, 30 min, $56^{\circ} \mathrm{C}$, Merck-Calbiochem, San Diego, USA), alkylation with iodoacetamide (50 mM, 30 min, room temperature, darkness, Fluka, St. Louis, USA) and digestion with $150 \mathrm{ng}$ trypsin (5 h, $37^{\circ} \mathrm{C}$ Promega, Sequencing Grade, Wisconsin, USA) using a Tecan Freedom EVO robotic liquid handler (Tecan Systems, Inc, San Jose, USA). Peptides were extracted with 50 $\mu \mathrm{l} 50 \%(\mathrm{v} / \mathrm{v})$ acetonitrile, $50 \mathrm{mM}$ ammonium bicarbonate, concentrated by centrifugal evaporation (Savant, Thermo-Fisher Scientific, USA) and re-solubilized in $20 \mu \mathrm{l} 2 \%(\mathrm{v} / \mathrm{v})$ acetonitrile, $0.1 \%$ formic acid, in water.

Peptides were analyzed on a LTQ Orbitrap Velos with nano electrospray ionization source (Thermo-Fisher Scientific, San Jose, CA) connected to a 1100 Series HPLC (Agilent Technologies, Santa Clara, CA) with an electronically controlled flow splitter for nano flow rates. Peptides were loaded to a trap column packed with ReproSil-Pur C18-AQ (15x0.075 mm I.D., $120 \AA$, $3 \mu \mathrm{m}$, Dr. Maisch, Ammerbuch-Entringen, Germany) for 6 min using 2\% 
acetonitrile, $0.1 \%$ formic acid in water at a flow rate of $3 \mu \mathrm{l} / \mathrm{min}$. Peptide separation was performed with an in-house packed capillary column (150x0.075 mm I.D., $120 \AA$, $3 \mu \mathrm{m}$, Dr. Maisch ReproSil-Pur C18-AQ, Ammerbuch-Entringen, Germany) using $0.1 \%$ formic acid in water $(A)$ and $0.1 \%$ formic acid in acetonitrile $(B)$ with a gradient from $2 \%$ to $35 \%$ in 60 min at a flow rate of $0.3 \mu \mathrm{l} / \mathrm{min}$. Survey full scan MS spectra were acquired in the mass range $\mathrm{m} / \mathrm{z}$ $300-1800$ in the Orbitrap analyzer at a resolution of 60,000. The five most intense ions in the survey scan were fragmented by collision-induced dissociation in the LTQ. Charge state one, and unassigned charges, were rejected. MS/MS spectra were acquired upon a minimal signal of 500 counts, with an isolation width of two and a normalized CE of 35. Dynamic exclusion was enabled to exclude precursors for $60 \mathrm{~s}$ after three observations. Raw mass spectrometry data is deposited in PeptideAtlas at http://www.peptideatlas.org/PASS/PASS00920.

Thermo Xcalibur .RAW files were converted to mzML using ProteoWizard msconvert (version 3.0.03495) [44, 45]. MS/MS spectra were searched with Comet (version 2015.02 rev 5) [46] against the mouse proteome obtained from UniProt (www.uniprot.org, release 2016_05), common contaminants and a sequence-shuffled decoy counterpart were appended to the database. Peptides were allowed to be semi-tryptic with up to two internal cleavage sites. The search parameters included a fixed modification of +57.021464 to account for carbamidomethylated cysteines and variable modifications of +15.994915 for oxidized methionines and +42.010565 for $\mathrm{N}$-terminal acetylation. The search results were processed with the Trans-Proteomic Pipeline (version 4.8.0 PHILAE) [47] including PeptideProphet [48], iProphet [49] and ProteinProphet [50]. Peptide spectrum matches (PSMs) generated by the search engine were analyzed with PeptideProphet to assign each PSM a probability of being correct. The accurate mass binning and nonparametric model were used in the PeptideProphet analysis. PeptideProphet results were further processed with iProphet to refine the PSM-level probabilities and compute peptide-level probabilities, and subsequently with ProteinProphet to calculate probabilities for protein identifications. Only proteins identified with a probability of $\geq 0.9$ in each sample corresponding to an error of $\leq 1 \%$ were considered in this analysis. For further analysis, we focused on proteins, which were uniquely identified in mineralized lesions but not in the surrounding intact tissue. Association of these proteins with functional pathways (KEGG) was derived by STRING (version 10, [51]) applying a minimum required interaction score of 0.9 (highest confidence). 


\section{Results}

\section{Reduced growth and premature death in fetuin-A deficient DBA/2 mice}

Over the course of several years we recorded the weight of a total of $>750$ random selected animals that were analyzed at ages 7-450 days in this or in related studies. Figures $1 \mathrm{~A}, \mathrm{~B}$ show that bodyweights of C57BL/6 (B6) and DBA/2 (D2) wildtype mice in our colony plateaued at 32 and 33 grams, respectively. Fetuin-A deficient B6 littermate mice similarly attained bodyweights of 34 grams. In contrast, fetuin-A deficient DBA/2 mice diverged in bodyweight from about 3 weeks onward, and attained reduced bodyweights of $26 \pm 3$ grams at the end of the observation period (Figure 1A). Importantly, we observed along the timeline outliers with less than half normal body weight, which had severe ectopic calcifications as shown in figures S1 A-H. Figures $1 \mathrm{C}, \mathrm{D}$ show the 12-month survival rates in B6,wt, B6,ko and D2, wt mice were higher than $90 \%$ regardless of sex. In contrast, the survival rates in $\mathrm{D} 2$,ko mice were reduced at $86 \%$ in male and $61 \%$ in female mice. We analyzed by echocardiography the cardiac output of isofluorane anesthetized mice at 4, 8, and 12 months age (Figure $\mathrm{S} 1 \mathrm{~J}$ ). Wildtype mice increased their cardiac output from $7.5 \pm 2.2 \mathrm{ml} / \mathrm{min}$ at 4 months age to $12.5 \pm 5 \mathrm{ml} / \mathrm{min}$ at 12 months in good agreement with published values for DBA/2 mice. In contrast, fetuin-A deficient mice had progressively reduced cardiac output ranging from $7 \pm 2 \mathrm{ml} / \mathrm{min}$ at four months to $6 \pm 1 \mathrm{ml} / \mathrm{min}$ at $8 \mathrm{months}$, and $5 \pm 1 \mathrm{ml} / \mathrm{min}$ at 12 months, respectively, suggesting worsening of cardiac function with age. Thus D2,ko mice most likely died of cardiac failure as heart function progressively deteriorated with calcification.

\section{Widespread ectopic calcification in D2,Ahsg-/- mice}

We performed X-ray-based computed tomography to survey ectopic mineralization in the entire bodies of living D2 mice (Figure 2). Apart from the expected mineralization of the skeleton and teeth, wildtype mice showed only minor amounts of mineral elsewhere in the gastrointestinal tract attributable to dietary mineral (Figure 2A). In contrast, D2,Ahsg-/- mice presented with severe and abundant mineralization spread throughout many soft tissues. We observed prominent mineral lesions in interscapular brown adipose tissue (BAT) (Figure 2B), surrounding the kidney and within the pelvis (Figure 2B), and in the axillae (Figure 2C). Computed tomography revealed mineralized lesions in the spleen and pancreas (Figure 2D), testes (Figure 2C), kidney and skin (Figure 2B-D, see also Supplemental Movies). Previously reported mineral-containing lesions in the lung and myocardium [29] remain undetected by computed tomography of live animals because of the motion disturbance caused by heartbeat and breathing movements; however, severe mineralization was indeed detected in these two organs by post mortem micro-computed tomography of excised organs (Supplemental Movies). Supplemental figures S1A-H show unstained tissues with nodular calcified lesions presenting as off-whitish, semi-transparent granules of sub-millimeter size. Nodules were present in the interscapular brown fat $(A)$, adrenal fat $(B)$, but not the kidney pelvis, of 6-week-old a D2,Ahsg-/- mice, as well as in the ventricular wall and the atrium (C), lung tissue $(D)$, spleen $(E)$, pancreas $(F)$, kidney pelvis $(G)$, and ovaries $(H)$ of 16-week old $\mathrm{D} 2$,Ahsg-/- mice. In summary, these mice had calcified lesions in most soft tissues by the age of four months. Next we studied the timing and tissue localization of calcification in D2, Ahsg-/- mice. 


\section{Calcification starts in the microvasculature}

We first performed an extensive screening of von Kossa-stained (for mineral) tissue sections derived from 52-week-old DBA/2 Ahsg-/- adult mice in order to get further insight into the microstructure and process of lesion formation. From this, we noted conspicuous mineralized lesions located in the lumen of the microvasculature. As examples, Figure 3 shows representative photomicrographs of intravascular mineralized lesions in the kidney (Figure $3 A, B$ ), adipose tissue (Figure 3C, D) and pancreas (Figure 3E). Red blood cells could be observed immediately adjacent to mineralized lesions (Figure $3 A-D$ ), further evidence that they were intravascular. Mineralized lesions were observed within arterial vessels including small arterioles (Figure 3B) as well as in small arteries (Figure 3A, C). Occasionally, wellrounded globular "stones" were observed (Figure 3E). Haematoxylin/eosin staining showed that all lesions were coagulum/protein-rich (Figure 3F, G). In most cases, however, the structure of the lesions was perturbed to some degree by sectioning. Another limitation of routine paraffin histology was that late-stage mineralized lesions were accompanied by widespread tissue remodeling and fibrosis, and it was thus difficult to render judgement on the process of primary lesion localization and morphology. To better address this, we performed transmission electron microscopy (TEM) of early-stage mineralization in intrascapular brown adipose tissue dissected from 2-week-old fetuin-A deficient DBA/2 mice, a tissue severely affected by the ectopic mineralization (Figure S1A). In agreement with our findings from von Kossa staining of adult mice, we detected mineralized, crystalline material within the blood vessels (Figure 4A-F). Intravascular lesions were detected in microvessels of all sizes ranging from capillaries (diameter 4-20 $\mu \mathrm{m}$, Figure 4D-F) to arterioles (diameter $35 \mu \mathrm{m}$, Figure 4A-C). The lesion shown in Figure 4A-C was surrounded by an endothelium (tunica intima) enclosed by a single layer of smooth muscle cells (tunica media) and the tunica externa, while the intravascular lesions shown in Figure 4D-F were surrounded by a single layer of endothelium characteristic of capillaries. Occasionally, red blood cells were enclosed by mineral precipitate (Figure 4D, E). Intravascular lesions were composed of organic, cellular and electron-dense crystalline structures. To confirm the presence of mineralized material in such lesions, we performed selected-area electron diffraction (SAED), X-ray diffraction (XRD) and energy-dispersive X-ray spectroscopy (EDS) on an intravascular lesion, first identified within a microvessel by toluidine blue staining of semi-thin sections (Figure 5A). EDS compositional probing of different areas of the lesion found calcium and phosphate as major elements present in the mineral (Figure 5B, D). SAED and XRD of the mineralized lesion showed diffraction maxima characteristic of a poorly crystallized apatitic mineral phase (Figure 5C, insets) as typically observed in biogenic apatites.

In order to further confirm the localization of the mineralized lesions within the microvasculature, we performed immunostaining for endothelial and lymphatic markers, and calcium/mineral-binding proteins, and examined these by fluorescence microscopy. We used two different techniques to detect mineralized lesions by immunofluorescence staining. Conventional antibody staining for osteopontin - a mineral-binding protein known to be abundant at mineralization sites [52] - was used to identify mineralized lesions. As a second method, we injected mice with bovine fetuin-A which, because of its strong calcium-binding properties, accumulates at mineralization sites. Immunofluorescence staining for OPN and for injected bovine fetuin-A detected small-diameter and moderate-sized mineralized lesions (Figure 6A-D). This high sensitivity allowed early detection of very small mineralized lesions at 2 weeks of age that could not be detected using routine histology or computed tomography. Figures $6 \mathrm{~A}$ and $6 \mathrm{C}$ show particularly well early-stage lesions clearly localized 
inside capillaries, as shown by surrounding CD31-positive vessels. In contrast, double staining with Lyve-1 revealed that there was no surrounding co-localization with lymphatic vessels (Figure 6D).

\section{Calcified lesions contain plasma proteins}

We next analyzed the composition of dissected calcified lesions in D2,Ahsg-/- mice with regard to their protein content. Figures $7 \mathrm{~A}-\mathrm{C}$ depict millimeter-sized lesions isolated from interscapular brown adipose tissue. Proteins were extracted from such mineralized lesions, and intact tissue was also dissected from interscapular brown adipose tissue, heart and skin, and separated using SDS-PAGE (Figure 7D). For mass spectrometry (MS) analysis of the protein content in the mineralized lesions, we focused on the most abundant bands of both intact control tissue and extracts of mineralized lesions. Association of these proteins with functional pathways revealed that lesions in all organs contained protein components of the complement and coagulation cascade (Table 1-3). The detection by MS of plasma proteins in mineralized lesions was consistent with the histology and TEM results, together indicating that mineralized lesions develop within the lumen of microvessels.

\section{Calcification is not associated with osteogenic differentiation and bone formation}

To elucidate the molecular pathways triggering soft tissue mineralization in these mice, we performed genome-wide gene expression analysis in DBA/2 wildtype and fetuin-A deficient mice. Figure 8 shows a volcano plot representation of the gene expression profile of kidney parenchyme and kidney-associated brown adipose tissue dissected from 5-6 week-old mice. In brown adipose tissue, severe mineralization is usually observed in 5-6 week-old mice enabling the detection of genes, which are differentially expressed as a result of the mineralization (Figure 8B). In the kidney, lesion formation starts considerably later. Thus, differential evaluation of the gene expression pattern in these two tissues may provide insights into the mechanisms preceding the formation of mineralized lesions. According to the different mineralization states in kidney parenchyme and kidney-associated brown adipose tissue, only minor changes in gene expression were observed in the kidney parenchyme (narrow shape of volcano plot, Figure $8 \mathrm{~A}$ ), whereas the severe mineralization that occurs in kidney-associated brown adipose tissue caused a dramatic change in gene expression in this tissue, in particular, the upregulation of several genes in D2,Ahsg-/- mice (broad shape of volcano plot, Figure 8B). In total, 16 differentially expressed genes ( $p$-value $<0.05$ ) were detected in the kidney (Table 4). In contrast, 395 differentially expressed genes were found in brown adipose tissue. The significantly regulated genes with a fold change above four (log-ratio $>3$ ) are summarized in Table 5.

The two most highly upregulated probe sets in the kidney encoded for solute carrier family 15 ( $\mathrm{H}+$ /peptide transporter), member 2 (Slc15a2) and were 14.1 and 6.2-fold increased in Ahsg/- kidneys, respectively. Slc15a2, also known as peptide transporter 2 (PEPT2), is expressed predominantly in the kidney and has been shown to be a proton-dependent transporter of diand tri-peptides [53]. Remarkably, neither this transporter nor any other of the differentially regulated genes was related to mineral transport or mineralization processes, suggesting that mineralization is not driven by genetic reprogramming of cells towards an osteoblastic phenotype.

In brown adipose tissue, 27 probe sets were more than 6-fold increased in D2,Ahsg-/- mice. Among the ten most highly upregulated probe sets, two members of the small proline rich 
(SPRR) protein family were found, a protein family previously associated with various inflammatory diseases, cellular stress and repair [54]. Sprr1a was 64.9-fold increased, Sprr2a was represented by two probe sets with 45.1- and 25.7-fold upregulation in Ahsg-/mice, respectively. The matrix metallopeptidase 12 (Mmp12), involved in extracellular remodeling, showed a fold change of 19.9. Secreted phosphoprotein 1 (Spp1, osteopontin), with a fold change of 17.3 , was detected as another highly upregulated probe set. Spp1/OPN is a secreted multifunctional glyco-phosphoprotein involved in mineral metabolism. Spp1 expression levels are found elevated in several chronic inflammatory disease pathologies [55] indicating chronic inflammation also caused by calcification. All significantly regulated probe sets were screened for biological function using the KEGG gene set. Table 6 lists ten gene sets, which were significantly overrepresented among the tested probe sets. Several pathways related to tissue remodeling, ECM-receptor interaction, cell cycle, p53 signaling, cell adhesion molecules and the Notch signaling pathway were amongst the differentially regulated pathways. Notably, no probe set directly associated with osteogenic differentiation or bone formation was differentially regulated. 


\section{Discussion}

In mice, the combination of the calcification-prone genetic background DBA/2 and fetuin-A deficiency leads to a spontaneous, severe ectopic mineralization, which occurs on a systemic level [29]. Soft tissue calcification is associated with cardiac failure and premature death. The full penetrance and severe expression of the calcification phenotype renders these mice ideal for studying mechanisms and therapeutic approaches for mineralization diseases. A concurrent study from our laboratory has shown that the severe soft tissue calcification in the mice is governed by fetuin- $A$, pyrophosphate and magnesium, and can in fact be prevented by prophylactic supplementation of each one of these major systemic inhibitors of calcification [30].The aim of this present study was to analyze the early events leading to soft tissue mineralization in these mice. We first used computed tomography to survey and identify organs affected by ectopic mineralization in living mice. In this way, we detected soft tissue calcification in heart, lung, spleen, pancreas, skin, and gonads, and for the first time, in brown adipose tissue. The high number of affected organs underscores the systemic nature of the mineralization phenotype. We focused on early stage lesions detected by von Kossa histology (Figure 3), TEM (Figure 4), or immunofluorescence (Figure 6).

Notably, affected tissues are all known to be highly capillarized. This particular observation is significant, because we show here that calcified lesions start in the lumen of microvessels. We further show by gene expression analysis of mineralized brown adipose tissue that the formation of mineralized lesions triggers robust tissue remodeling. Thus, the morphology of the tissue in proximity to the mineralized lesions is quickly and thoroughly remodeled, precluding a detailed analysis of mineralization-triggering events. To overcome this limitation, monitoring of early-stage lesions or even the growth process of small mineralized lesions would be preferable, but this is not yet accessible because of the limited resolution of in vivo imaging methods and devices for small rodents, and because of the fast spreading of mineralized lesions once started. Despite these limitations in methodology, we did in fact observe many intravascular lesions using advanced imaging methods on harvested tissues, including electron microscopy, supporting the notion that mineralization in D2,Ahsg-/- mice starts in the lumen of the vasculature. This contrasts to some extent with currently prevailing dogma (despite reservations on this, ref. [56]) stating that ectopic mineralization involves osteo/chondral differentiation of resident cells, therefore recapitulating bone formation. Instead, mineralization in D2,Ahsg-/- mice emphasizes the regulation by fetuin-A of mineralization deriving from complex solutions, a notion that has been repeatedly demonstrated in collagen mineralization $[57,58]$. Recent work on crystal growth challenges classical nucleation theory and stresses the importance of particle attachment in synthetic, biogenic, and geologic environments [59]. Synthetic and natural polymers have been shown by many laboratories to maintain high supersaturation by forming colloidal particles, and to control mineralization. Mineral-containing particles have recently also been described to provide bulk mineral for bone mineralization $[60,61]$. We suggest here that fetuin-A is a prototype natural polymer involved in colloidal mineral particle formation and stabilization in vertebrates. Fetuin-A is an abundant plasma protein, and low plasma levels have been variably related to mineralization-associated diseases [19-24]. We and others have shown that fetuin-A is a main component of colloidal mineral-protein particles found in supersaturated calcium-phosphate solution in vitro $[6,7]$ and in serum of CKD patients [11, 62]. Most importantly, fetuin-A is crucial for the formation and stabilization of calciprotein particles (CPP) [4, 6], which subsequently mediate the clearance of excess calciumphosphate by macrophages in liver and spleen $[3,5]$. Considering the high serum calcium 
and phosphate concentration, even under physiological conditions, it is not surprising that fetuin-A deficiency results in precipitation of calcium-phosphate directly from the circulation. Precipitating calcium-phosphate mineral may then serve as a solid phase for blood coagulation explaining the presence of coagulation factors detected by protein MS in calcified lesions. Furthermore, our analysis of the protein content of mineralized lesions revealed a striking similarity to serum granulations derived from human or bovine serum mixed with calcium, phosphate, or both, which were studied by Young and colleagues [7, 63]. The granules contained various plasma proteins, including components of the complement system, all likewise detected in calcified lesions of D2,Ahsg-/- mice (Figure 7, Table 1-3, Supplementary Table 1). The striking similarity in protein content of serum granules and calcified lesions studied here suggests similar mechanisms of mineral formation and most importantly the participation of serum. At this time, it is not clear whether the protein composition in mineralized lesions merely reflects the relative abundance of proteins in the given environment as previously discussed by Young et al. [7], or if there is a selective enrichment of the identified proteins.

Ectopic mineralization has been studied in great detail in association with atherosclerosis and vascular calcification. The identification of matrix vesicles in mineralized vasculature [64$66]$, the detection of bone-associated proteins in human atherosclerotic plaques [67,68], and the overexpression of several mineralization-associated transcription factors [69-72] led to the view that calcification in general comprises an active biological process including osteogenic transdifferentiation of vascular smooth muscle cells. A similar mechanism was suggested for valvular calcification [73]. In contrast, a DNA microarray analysis of human calcified aortic valves detected elevated inflammatory markers but no upregulation of osteoblastic markers [74]. In addition, it was shown that the deposition of calcium-phosphate was passive and the osteogenic differentiation of VSMCs happened after the initial calcification [56, 75]. These findings were confirmed in breast arterial calcification in CKD patients and in arterial calcification of $5 / 6^{\text {th }}$ nephrectomized rats on high phosphate diet [7678]. Thus, it seems that osteochondral cell differentiation is consequence, rather than a cause, of mineralization in soft tissues. With this in mind, we interrogated osteogenic and other gene regulatory networks by a genome-wide gene expression study in kidney and brown adipose tissue dissected from DBA/2 wildtype and Ahsg-/- mice. The kidney, when examined in a "pre-mineralization state" essentially shows no differentially expressed genes suggesting a process of chemical mineral precipitation rather than bone formation processes involving different differentiated cell states. In late-stage ectopic mineralization, as was analyzed in brown adipose tissue, we likewise failed to detect any genes or pathways related to mineralization or osteogenic processes. Instead, we identified 395 differentially regulated genes, most of which were upregulated in the D2,Ahsg-/- mouse, and which were associated with inflammatory signaling and remodeling processes. Among the most highly upregulated genes we identified two members of the small proline-rich protein family, SPRR1A and SPRR2A. Both have been associated with various inflammatory diseases including inflammatory skin diseases [79], allergic inflammation [80] and fibrosis [54]. In addition, a stress-related induction of Sprr1a in cardiomyocytes and a protective effect against ischemic injury was described [81]. Thus, increased expression of Sprr1a in mineralized brown adipose tissue in Ahsg-/- mice may reflect the pro-fibrotic stimulus of mineralization. A 17.3fold increase in Spp1/OPN expression was detected confirming the previous detection of OPN in mineralized lesions of D2,Ahsg-/- mice [52], in uremic C57BL/6,Ahsg-/- mice [82], and in mineralized human coronary arteries $[67,83]$. It was shown that mineralization- 
associated OPN is secreted by macrophages, which commonly accumulates in mineralized lesions [52]. Various functions of OPN have been proposed. Steitz and colleagues reported that OPN physiologically blocked crystal growth by induction of carbonic anhydrase 2 and thus by acidification of the extracellular milieu [84]. An inhibitory role for OPN was confirmed in MGP-deficient mice where genetic ablation of OPN further enhanced the mineralization phenotype [85]. OPN accumulation was however not associated with reduced levels of mineralization in D2,Ahsg-/- mice. Thus, OPN expression seemed to be reactive rather than preventive. Beside its role in mineralization, OPN has been described in association with a broad spectrum of immunomodulatory functions including chemotactic macrophage infiltration [55]. Thus, OPN expression in mineralized brown adipose tissue may reflect a role in the recruitment of macrophages and leukocytes. Another highly upregulated gene in mineralized brown adipose tissue was MMP12, which cleaves CXC type chemokines and may therefore play a key role in regulation of active inflammatory responses by terminating the influx of polymorphonuclear leukocytes [86]. Here, an increased MMP12 expression may explain the relatively moderate degree of mineralization-associated inflammation

(Supplemental Figure 2); while macrophage accumulation was observed in most the cases, polymorphonuclear leukocytes were only detected occasionally at mineralization sites. In conclusion, our gene expression analysis revealed an activation of genes involved in tissue remodeling and inflammation in late-stage mineralization. The microarray analysis presented here did not indicate that mineralization in D2,Ahsg-/- mice involves any osteogenic conversion of cells. Instead, our data strongly supports the notion that fetuin-A deficiency in D2,Ahsg-/- mice triggers systemic ectopic mineralization in the microvasculature. Thus, chemical mineral precipitation in blood causes ischemia, tissue necrosis and fibrotic-calcific remodeling in fetuin-A-deficient DBA/2 mice.

In summary, fetuin-A is a well known systemic inhibitor of ectopic mineral deposition. Although the mechanisms of mineral inhibition has been studied in great detail previously, it has not been clear as to which molecular events lead to the severe soft tissue mineralization seen in D2,Ahsg-/- mice. Here, we report that ectopic mineralization in these mice occurs within the microvasculature due to the absence of the fetuin-A mediated solubilization and clearance of excess calcium-phosphate from the circulation.

\section{Acknowledgments}

We thank the Genomics-facility of IZKF Aachen for performing the gene expression arrays.

\section{Sources of Funding}

This work was supported by grants awarded to WJD by the IZKF Aachen of the Medical Faculty of RWTH Aachen and by the German Research Foundation (DFG SFB/TRR219Project C-03). This work was also funded in part by National Institutes of Health from the National Institute of General Medical Sciences (NIGMS) grants R01GM087221, S10RR027584 and 2P50GM076547 to the Center for Systems Biology, the National Science Foundation MRI grant 0923536, and the Canadian Institutes of Health Research. We thank Sarah Li and Lydia Malynowsky for expert technical assistance. MDM is a member of the FRQS Network for Oral and Bone Health Research. 
bioRxiv preprint doi: https://doi.org/10.1101/577098; this version posted October 4, 2019. The copyright holder for this preprint (which was not certified by peer review) is the author/funder. All rights reserved. No reuse allowed without permission.

\section{Disclosures}

All authors declare no conflict of interest related to this work. 


\section{References}

1. Herrmann M, Babler A, Moshkova I, Gremse F, Kiessling F, Kusebauch U, et al. Luminal Calcification of the Microvasculature in Fetuin-A Deficient Mice Leads to Premature Aging and Death. bioRxiv. 2019:577098. doi: 10.1101/577098.

2. Block G, Klassen P, Lazarus J, Ofsthun N, Lowrie E, Chertow GM. Mineral metabolism, mortality, and morbidity in maintenance hemodialysis. J Am Soc Nephrol. 2004;15(8):2208-18. PubMed PMID: 15284307.

3. Koeppert S, Büscher A, Babler A, Ghallab A, Buhl EM, Latz E, et al. Cellular Clearance and Biological Activity of Calciprotein Particles Depend on Their Maturation State and Crystallinity. Frontiers Immunol. 2018;9:1991. doi: 10.3389/fimmu.2018.01991. PubMed PMID: 30233585; PubMed Central PMCID: PMCPMC6131296.

4. Wald J, Wiese S, Eckert T, Jahnen-Dechent W, Richtering W, Heiss A. Formation and stability kinetics of calcium phosphate-fetuin-A colloidal particles probed by timeresolved dynamic light scattering. Soft Matter. 2011;7:2869-74. PubMed PMID: related:capZVPZigvUJ.

5. Herrmann M, Schäfer C, Heiss A, Gräber S, Kinkeldey A, Büscher A, et al. Clearance of fetuin-A-containing calciprotein particles is mediated by scavenger receptor-A. Circ Res. 2012;111(5):575-84. doi: 10.1161/CIRCRESAHA.111.261479. PubMed PMID: 22753077.

6. Heiss A, Eckert T, Aretz A, Richtering W, Van Dorp W, Schafer C, et al. Hierarchical Role of Fetuin-A and Acidic Serum Proteins in the Formation and Stabilization of Calcium Phosphate Particles. J Biol Chem. 2008;283(21):14815-25. doi: 10.1074/jbc.M709938200.

7. Young JD, Martel J, Young D, Young A, Hung C-M, Young L, et al. Characterization of granulations of calcium and apatite in serum as pleomorphic mineralo-protein complexes and as precursors of putative nanobacteria. PLoS ONE. 2009;4(5):e5421. doi: 10.1371/journal.pone.0005421. PubMed PMID: 19412552.

8. Price PA, Nguyen TMT, Williamson MK. Biochemical characterization of the serum fetuin-mineral complex. J Biol Chem. 2003;278(24):22153-60. doi: 10.1074/jbc.M300739200. PubMed PMID: 12676928.

9. Matsui I, Hamano T, Mikami S, Fujii N, Takabatake Y, Nagasawa Y, et al. Fully phosphorylated fetuin-A forms a mineral complex in the serum of rats with adenineinduced renal failure. Kidney Int. 2009;75(9):915-28. doi: 10.1038/ki.2008.700. PubMed PMID: 19190677.

10. Olde Loohuis KM, Jahnen-Dechent W, van Dorp W. The case: milky ascites is not always chylous. Kidney Int. 2010;77(1):77-8. doi: 10.1038/ki.2009.407. PubMed PMID: 20010886.

11. Hamano T, Matsui I, Mikami S, Tomida K, Fujii N, Imai E, et al. Fetuin-mineral complex reflects extraosseous calcification stress in CKD. J Am Soc Nephrol. 2010;21(11):1998-2007. doi: 10.1681/ASN.2009090944. PubMed PMID: 20947626.

12. Smith ER, Cai MM, McMahon LP, Pedagogos E, Toussaint ND, Brumby C, et al. Serum fetuin-A concentration and fetuin-A-containing calciprotein particles in patients with chronic inflammatory disease and renal failure. Nephrology (Carlton). 2013;18(3):215-21. doi: 10.1111/nep.12021. PubMed PMID: 23231493.

13. Miura Y, Iwazu Y, Shiizaki K, Akimoto T, Kotani K, Kurabayashi M, et al. Identification and quantification of plasma calciprotein particles with distinct physical properties in patients with chronic kidney disease. Sci Rep. 2018:1-16. doi: 10.1038/s41598-01819677-4.

14. Smith ER, Hewitson TD, Cai MMX, Aghagolzadeh P, Bachtler M, Pasch A, et al. A novel fluorescent probe-based flow cytometric assay for mineral-containing nanoparticles in serum. Sci Rep. 2017;7(1):5686. doi: 10.1038/s41598-017-05474-y. PubMed PMID: 28720774; PubMed Central PMCID: PMCPMC5515983.

15. Pasch A, Farese S, Gräber S, Wald J, Richtering W, Floege J, et al. Nanoparticlebased test measures overall propensity for calcification in serum. J Am Soc Nephrol. 2012;23(10):1744-52. doi: 10.1681/ASN.2012030240. PubMed PMID: 22956818.

16. Smith ER, Ford ML, Tomlinson LA, Bodenham E, McMahon LP, Farese S, et al. Serum calcification propensity predicts all-cause mortality in predialysis CKD. J Am Soc 
Nephrol. 2014;25(2):339-48. doi: 10.1681/ASN.2013060635. PubMed PMID: 24179171; PubMed Central PMCID: PMCPMC3904573.

17. Ferrer MD, Pérez MM, Cànaves MM, Buades JM, Salcedo C, Perelló J. A novel pharmacodynamic assay to evaluate the effects of crystallization inhibitors on calcium phosphate crystallization in human plasma. Sci Rep. 2017;7(1):6858. doi: 10.1038/s41598-017-07203-x. PubMed PMID: 28761091; PubMed Central PMCID: PMCPMC5537272.

18. Lorenz G, Steubl D, Kemmner S, Pasch A, Koch-Sembdner W, Pham D, et al. Worsening calcification propensity precedes all-cause and cardiovascular mortality in haemodialyzed patients. Sci Rep. 2017;7(1):13368. doi: 10.1038/s41598-017-12859-6. PubMed PMID: 29042624; PubMed Central PMCID: PMCPMC5645333.

19. Ketteler M, Bongartz P, Westenfeld R, Wildberger J, Mahnken A, Bohm R, et al. Association of low fetuin-A (AHSG) concentrations in serum with cardiovascular mortality in patients on dialysis: a cross-sectional study. Lancet. 2003;361(9360):82733. doi: 10.1016/S0140-6736(03)12710-9. PubMed PMID: 12642050.

20. Ix JH, Chertow GM, Shlipak MG, Brandenburg VM, Ketteler M, Whooley MA. Association of fetuin-A with mitral annular calcification and aortic stenosis among persons with coronary heart disease: data from the Heart and Soul Study. Circulation. 2007;115(19):2533-9. doi: 10.1161/CIRCULATIONAHA.106.682450. PubMed PMID: 17485576.

21. Stejskal D, Karpisek M, Vrtal R, Student V, Solichova P, Fiala R, et al. Urine fetuin-A values in relation to the presence of urolithiasis. BJU Int. 2008;101(9):1151-4. doi: 10.1111/j.1464-410X.2007.07432.x. PubMed PMID: 18190622.

22. Koos R, Brandenburg V, Mahnken AH, Mühlenbruch G, Stanzel S, Günther RW, et al. Association of fetuin-A levels with the progression of aortic valve calcification in nondialyzed patients. Eur Heart J. 2009;30(16):2054-61. doi: 10.1093/eurheartj/ehp158. PubMed PMID: 19429630.

23. Bilgir O, Kebapcilar L, Bilgir F, Bozkaya G, Yildiz Y, Pinar P, et al. Decreased serum fetuin-A levels are associated with coronary artery diseases. Intern Med. 2010;49(13):1281-5. Epub 2010/07/08. PubMed PMID: 20606360.

24. Eraso LH, Ginwala N, Qasim AN, Mehta NN, Dlugash R, Kapoor S, et al. Association of lower plasma fetuin-a levels with peripheral arterial disease in type 2 diabetes. Diabetes care. 2010;33(2):408-10. doi: 10.2337/dc09-1541. PubMed PMID: 19910501.

25. Shook LL, Buhimschi CS, Dulay AT, McCarthy ME, Hardy JT, Duzyj Buniak CM, et al. Calciprotein particles as potential etiologic agents of idiopathic preterm birth. Science translational medicine. 2016;8(364):364ra154-364ra154. doi: 10.1126/scitranslmed.aah4707. PubMed PMID: 27831903.

26. Ball CR, Williams WL. Spontaneous and dietary-induced cardiovascular lesions in DBA mice. Anat Rec. 1965;152(2):199-209. PubMed PMID: 5842161.

27. Brunnert SR. Morphologic response of myocardium to freeze-thaw injury in mouse strains with dystrophic cardiac calcification. Lab Anim Sci. 1997;47(1):11-8. PubMed PMID: 9051642.

28. Eaton GJ, Custer RP, Johnson FN, Stabenow KT. Dystrophic cardiac calcinosis in mice: genetic, hormonal, and dietary influences. Am J Pathol. 1978;90(1):173-86. PubMed PMID: 145807.

29. Schäfer C, Heiss A, Schwarz A, Westenfeld R, Ketteler M, Floege J, et al. The serum protein alpha 2-Heremans-Schmid glycoprotein/fetuin-A is a systemically acting inhibitor of ectopic calcification. J Clin Invest. 2003;112(3):357-66. doi: 10.1172/JCl17202. PubMed PMID: 12897203.

30. Babler A, Schmitz C, Buescher A, Herrmann M, Gremse F, Gorgels TG, et al. Soft tissue calcification in mice is governed by fetuin-A, pyrophosphate and magnesium. bioRxiv. 2019:577239. doi: 10.1101/577239.

31. Brylka LJ, Koeppert S, Babler A, Kratz B, Denecke B, Yorgan TA, et al. Post-weaning epiphysiolysis causes distal femur dysplasia and foreshortened hindlimbs in fetuin-Adeficient mice. PLoS ONE. 2017;12(10):e0187030. doi: 10.1371/journal.pone.0187030. PubMed PMID: 29088242; PubMed Central PMCID: PMCPMC5663435.

32. Merx MW, Schäfer C, Westenfeld R, Brandenburg V, Hidajat S, Weber C, et al. Myocardial stiffness, cardiac remodeling, and diastolic dysfunction in calcification- 
prone fetuin-A-deficient mice. J Am Soc Nephrol. 2005;16(11):3357-64. doi: 10.1681/ASN.2005040365. PubMed PMID: 16177000.

33. Lanzer P, Boehm M, Sorribas V, Thiriet M, Janzen J, Zeller T, et al. Medial vascular calcification revisited: review and perspectives. European heart journal. 2014;35(23):1515-25. doi: 10.1093/eurheartj/ehu163. PubMed PMID: 24740885; PubMed Central PMCID: PMCPMC4072893.

34. Gremse F, Stärk M, Ehling J, Menzel JR, Lammers T, Kiessling F. Imalytics Preclinical: Interactive Analysis of Biomedical Volume Data. Theranostics. 2016;6(3):328-41. doi: 10.7150/thno.13624. PubMed PMID: 26909109; PubMed Central PMCID: PMCPMC4737721.

35. Gentleman RC, Carey VJ, Bates DM, Bolstad B, Dettling M, Dudoit S, et al. Bioconductor: open software development for computational biology and bioinformatics. Genome Biol. 2004;5(10):R80. doi: 10.1186/gb-2004-5-10-r80. PubMed PMID: 15461798.

36. Kauffmann A, Gentleman R, Huber W. arrayQualityMetrics--a bioconductor package for quality assessment of microarray data. Bioinformatics. 2009;25(3):415-6. doi: 10.1093/bioinformatics/btn647. PubMed PMID: 19106121.

37. Gautier L, Cope L, Bolstad BM, Irizarry RA. affy--analysis of Affymetrix GeneChip data at the probe level. Bioinformatics. 2004;20(3):307-15. doi: 10.1093/bioinformatics/btg405. PubMed PMID: 14960456.

38. Gentleman R, Carey V, Huber W, Hahne F. Genefilter: methods for filtering genes from microarray experiments. R package version 1242 .

39. Pollard K, Gilbert H, Ge Y, Taylor S, Dudoit S. Multtest: Resampling-based multiple hypothesis testing. R package version 211. 2009.

40. Smith C. Annaffy: Annotation tools for Affymetrix biological metadata. R package version 1160. 2008.

41. Gentleman R. Annotate: Annotation for microarrays. R package version 1220.

42. Carlson M, Falcon S, Pages H, Li N. Mouse4302.db: Affymetrix Mouse Genome 430 2.0 Array annotation data (chip mouse4302). R package version 2211.

43. Morgan M, Falcon S, Gentleman R. GSEABase: Gene set enrichment data structures and methods. R package version 161.

44. Kessner D, Chambers M, Burke R, Agus D, Mallick P. ProteoWizard: open source software for rapid proteomics tools development. Bioinformatics. 2008;24(21):2534-6. doi: 10.1093/bioinformatics/btn323.

45. Martens L, Chambers M, Sturm M, Kessner D, Levander F, Shofstahl J, et al. mzML - a Community Standard for Mass Spectrometry Data. Molecular \& Cellular Proteomics. 2011;10(1):R110.000133. doi: 10.1074/mcp.R110.000133.

46. Eng JK, Jahan TA, Hoopmann MR. Comet: An open-source MS/MS sequence database search tool. PROTEOMICS. 2013;13(1):22-4. doi: 10.1002/pmic.201200439.

47. Deutsch EW, Mendoza L, Shteynberg D, Slagel J, Sun Z, Moritz RL. Trans-Proteomic Pipeline, a standardized data processing pipeline for large-scale reproducible proteomics informatics. PROTEOMICS - Clinical Applications. 2015;9(7-8):745-54. doi: 10.1002/prca.201400164.

48. Keller A, Nesvizhskii Al, Kolker E, Aebersold R. Empirical Statistical Model To Estimate the Accuracy of Peptide Identifications Made by MS/MS and Database Search. Analytical Chemistry. 2002;74(20):5383-92. doi: 10.1021/ac025747h.

49. Shteynberg D, Deutsch EW, Lam H, Eng JK, Sun Z, Tasman N, et al. iProphet: Multilevel Integrative Analysis of Shotgun Proteomic Data Improves Peptide and Protein Identification Rates and Error Estimates. Mol Cell Proteomics. 2011;10(12):M111.007690. doi: 10.1074/mcp.M111.007690.

50. Nesvizhskii A, Keller A, Kolker E, Aebersold R. A statistical model for identifying proteins by tandem mass spectrometry. Anal Chem. 2003;75:4646 - 58. PubMed PMID: doi:10.1021/ac0341261.

51. Szklarczyk D, Franceschini A, Wyder S, Forslund K, Heller D, Huerta-Cepas J, et al. STRING v10: protein-protein interaction networks, integrated over the tree of life. Nucleic Acids Res. 2015;43(Database issue):D447-52. doi: 10.1093/nar/gku1003. PubMed PMID: 25352553; PubMed Central PMCID: PMCPMC4383874.

52. Jahnen-Dechent W, Schäfer C, Ketteler M, McKee MD. Mineral chaperones: a role for 
fetuin-A and osteopontin in the inhibition and regression of pathologic calcification. $J$ Mol Med. 2008;86(4):379-89. doi: 10.1007/s00109-007-0294-y. PubMed PMID: 18080808.

53. Rubio-Aliaga I, Boll M, Daniel $\mathrm{H}$. Cloning and characterization of the gene encoding the mouse peptide transporter PEPT2. Biochem Biophys Res Commun. 2000;276(2):73441. doi: 10.1006/bbrc.2000.3546. PubMed PMID: 11027540.

54. Zheng L, Zhou Z, Lin L, Alber S, Watkins S, Kaminski N, et al. Carbon monoxide modulates alpha-smooth muscle actin and small proline rich-1a expression in fibrosis. American Journal of Respiratory Cell and Molecular Biology. 2009;41(1):85-92. doi: 10.1165/rcmb.2007-04010C. PubMed PMID: 19097987.

55. Lok ZSY, Lyle AN. Osteopontin in Vascular Disease. ATVB. 2019;27:ATVBAHA118311577. doi: 10.1161/ATVBAHA.118.311577. PubMed PMID: 30727754.

56. Murshed M, McKee MD. Molecular determinants of extracellular matrix mineralization in bone and blood vessels. Current Opinion in Nephrology and Hypertension. 2010;19(4):359-65. doi: 10.1097/MNH.0b013e3283393a2b. PubMed PMID: 20489614.

57. Price PA, Toroian D, Lim JE. Mineralization by inhibitor exclusion: the calcification of collagen with fetuin. J Biol Chem. 2009;284(25):17092-101. doi: 10.1074/jbc.M109.007013. PubMed PMID: 19414589; PubMed Central PMCID: PMCPMC2719347.

58. Nudelman F, Pieterse K, George A, Bomans PH, Friedrich H, Brylka LJ, et al. The role of collagen in bone apatite formation in the presence of hydroxyapatite nucleation inhibitors. Nat Mater. 2010;9(12):1004-9. doi: 10.1038/nmat2875. PubMed PMID: 20972429; PubMed Central PMCID: PMCPMC3084378.

59. De Yoreo JJ, Gilbert PUPA, Sommerdijk NAJM, Penn RL, Whitelam S, Joester D, et al. CRYSTAL GROWTH. Crystallization by particle attachment in synthetic, biogenic, and geologic environments. Science. 2015;349(6247):6760. doi: 10.1126/science.aaa6760. PubMed PMID: 26228157.

60. Akiva A, Malkinson G, Masic A, Kerschnitzki M, Bennet M, Fratzl P, et al. On the pathway of mineral deposition in larval zebrafish caudal fin bone. Bone. 2015;75:192200. doi: 10.1016/j.bone.2015.02.020. PubMed PMID: 25725266.

61. Kerschnitzki M, Akiva A, Ben Shoham A, Koifman N, Shimoni E, Rechav K, et al. Transport of membrane-bound mineral particles in blood vessels during chicken embryonic bone development. Bone. 2016;83:65-72. doi: 10.1016/j.bone.2015.10.009. PubMed PMID: 26481471.

62. Smith ER, Ford ML, Tomlinson LA, Rajkumar C, McMahon LP, Holt SG. Phosphorylated fetuin-A-containing calciprotein particles are associated with aortic stiffness and a procalcific milieu in patients with pre-dialysis CKD. Nephrol Dial Transplant. 2012;27(5):1957-66. doi: 10.1093/ndt/gfr609.

63. Wu C-Y, Martel J, Young D, Young JD. Fetuin-A/albumin-mineral complexes resembling serum calcium granules and putative nanobacteria: demonstration of a dual inhibition-seeding concept. PLoS ONE. 2009;4(11):e8058. doi: 10.1371/journal.pone.0008058. PubMed PMID: 19956594.

64. Kim KM. Calcification of matrix vesicles in human aortic valve and aortic media. Fed Proc. 1976;35(2):156-62. PubMed PMID: 1248649.

65. Tanimura A, McGregor DH, Anderson HC. Calcification in atherosclerosis. I. Human studies. J Exp Pathol. 1986;2(4):261-73. PubMed PMID: 2946818.

66. Kockx MM, Muhring J, Bortier H, De Meyer GR, Jacob W. Biotin- or digoxigeninconjugated nucleotides bind to matrix vesicles in atherosclerotic plaques. Am J Pathol. 1996;148(6):1771-7. PubMed PMID: 8669464.

67. Shanahan CM, Cary NR, Metcalfe JC, Weissberg PL. High expression of genes for calcification-regulating proteins in human atherosclerotic plaques. J Clin Invest. 1994;93(6):2393-402. doi: 10.1172/JCI117246. PubMed PMID: 8200973.

68. Boström K, Watson KE, Stanford WP, Demer LL. Atherosclerotic calcification: relation to developmental osteogenesis. Am J Cardiol. 1995;75(6):88B-91B. PubMed PMID: 7863982.

69. Steitz SA, Speer MY, Curinga G, Yang HY, Haynes P, Aebersold R, et al. Smooth muscle cell phenotypic transition associated with calcification: upregulation of $\mathrm{Cbfa} 1$ 
and downregulation of smooth muscle lineage markers. Circ Res. 2001;89(12):114754. PubMed PMID: 11739279.

70. Shioi A, Mori K, Jono S, Wakikawa T, Hiura Y, Koyama H, et al. Mechanism of atherosclerotic calcification. Z Kardiol. 2000;89 Suppl 2:75-9. PubMed PMID: 10769407.

71. Tyson KL, Reynolds JL, McNair R, Zhang Q, Weissberg PL, Shanahan CM. Osteo/chondrocytic transcription factors and their target genes exhibit distinct patterns of expression in human arterial calcification. Arterioscler Thromb Vasc Biol. 2003;23(3):489-94. doi: 10.1161/01.ATV.0000059406.92165.31. PubMed PMID: 12615658.

72. Towler DA, Bidder M, Latifi T, Coleman T, Semenkovich CF. Diet-induced diabetes activates an osteogenic gene regulatory program in the aortas of low density lipoprotein receptor-deficient mice. J Biol Chem. 1998;273(46):30427-34. PubMed PMID: 9804809.

73. Kaden JJ, Bickelhaupt S, Grobholz R, Haase KK, Sarikoç A, Kiliç R, et al. Receptor activator of nuclear factor kappaB ligand and osteoprotegerin regulate aortic valve calcification. J Mol Cell Cardiol. 2004;36(1):57-66. PubMed PMID: 14734048.

74. Anger T, Carson W, Weyand M, Daniel WG, Hoeher M, Garlichs CD. Atherosclerotic inflammation triggers osteogenic bone transformation in calcified and stenotic human aortic valves: still a matter of debate. Exp Mol Pathol. 2009;86(1):10-7. doi: 10.1016/j.yexmp.2008.11.001. PubMed PMID: 19084515.

75. Villa-Bellosta R, Millan A, Sorribas V. Role of calcium-phosphate deposition in vascular smooth muscle cell calcification. Am J Physiol, Cell Physiol. 2011;300(1):210-20. doi: 10.1152/ajpcell.00229.2010. PubMed PMID: 20881235.

76. O'Neill WC, Adams AL. Breast arterial calcification in chronic kidney disease: absence of smooth muscle apoptosis and osteogenic transdifferentiation. Kidney Int. 2014;85(3):668-76. doi: 10.1038/ki.2013.351. PubMed PMID: 24048381.

77. Hortells L, Sosa C, Guillén N, Lucea S, Millán Á, Sorribas V. Identifying early pathogenic events during vascular calcification in uremic rats. Kidney Int. 2017;92(6):1384-94. doi: 10.1016/j.kint.2017.06.019. PubMed PMID: 28844316.

78. O'Neill WC. Understanding the pathogenesis of vascular calcification: timing is everything. Kidney Int. 2017;92(6):1316-8. doi: 10.1016/j.kint.2017.07.020. PubMed PMID: 29153135.

79. De Heller-Milev M, Huber M, Panizzon R, Hohl D. Expression of small proline rich proteins in neoplastic and inflammatory skin diseases. Br J Dermatol. 2000;143(4):73340. PubMed PMID: 11069449.

80. Zimmermann N, Doepker MP, Witte DP, Stringer KF, Fulkerson PC, Pope SM, et al. Expression and regulation of small proline-rich protein 2 in allergic inflammation. Am J Respir Cell Mol Biol. 2005;32(5):428-35. doi: 10.1165/rcmb.2004-0269OC. PubMed PMID: 15731505.

81. Pradervand S, Yasukawa H, Muller OG, Kjekshus H, Nakamura T, St Amand TR, et al. Small proline-rich protein $1 \mathrm{~A}$ is a gp130 pathway- and stress-inducible cardioprotective protein. EMBO J. 2004;23(22):4517-25. doi: 10.1038/sj.emboj.7600454. PubMed PMID: 15510217.

82. Westenfeld R, Schäfer C, Smeets R, Brandenburg VM, Floege J, Ketteler M, et al. Fetuin-A (AHSG) prevents extraosseous calcification induced by uraemia and phosphate challenge in mice. Nephrol Dial Transplant. 2007;22(6):1537-46. doi: 10.1093/ndt/gfm094. PubMed PMID: 17389622.

83. Fitzpatrick LA, Severson A, Edwards WD, Ingram RT. Diffuse calcification in human coronary arteries. Association of osteopontin with atherosclerosis. J Clin Invest. 1994;94(4):1597-604. doi: 10.1172/JCl117501. PubMed PMID: 7929835.

84. Steitz SA, Speer MY, McKee MD, Liaw L, Almeida M, Yang H, et al. Osteopontin inhibits mineral deposition and promotes regression of ectopic calcification. Am J Pathol. 2002;161(6):2035-46. doi: 10.1016/S0002-9440(10)64482-3. PubMed PMID: 12466120.

85. Speer MY, McKee MD, Guldberg RE, Liaw L, Yang H-Y, Tung E, et al. Inactivation of the osteopontin gene enhances vascular calcification of matrix Gla protein-deficient mice: evidence for osteopontin as an inducible inhibitor of vascular calcification in vivo. 
J Exp Med. 2002;196(8):1047-55. PubMed PMID: 12391016.

86. Dean RA, Cox JH, Bellac CL, Doucet A, Starr AE, Overall CM. Macrophage-specific metalloelastase (MMP-12) truncates and inactivates ELR+CXC chemokines and generates CCL2, $-7,-8$, and -13 antagonists: potential role of the macrophage in terminating polymorphonuclear leukocyte influx. Blood. 2008;112(8):3455-64. doi: 10.1182/blood-2007-12-129080. PubMed PMID: 18660381. 


\section{Figure Legends}

Figure 1 Impaired growth and premature death in fetuin-A deficient DBA/2 mice

A, B, Random selected mice from the colony were weighed each at the day they were sacrificed for imaging or tissue harvest. Note that overall, B6,wt $(n=213) B 6, k o(n=205)$, and D2,wt mice $(n=138)$ all attained a maximum weight of $30 \pm 5$ gram while $D 2$, ko mice $(n=244)$ weighed in at roughly five gram lighter. The $95 \%$ confidence intervals of body weights are plotted as grey lines flanking the black fitted weight curves in each case. Outlier D2,ko mice with less than half normal body weight invariably were the most calcified upon autopsy (figure 6 and figure S1). C, D, The 12-month survival rate in B6,wt, B6,ko and D2, wt mice was higher than $90 \%$ regardless of sex and genetic background. In contrast the survival rates in $\mathrm{D} 2$, ko mice were reduced at $86 \%$ in male and $61 \%$ in female mice.

\section{Figure 2. Typical examples of adult calcified D2,Ahsg-/- mice}

Computed tomography of $(A)$ a male wildtype control mouse at 30 weeks of age, and (B-D) D2,Ahsg -/- mice at 20 weeks (B, C) or 35 weeks (D) of age. (A) Mineral in the skeleton, and food-derived mineral speckling in the GI tract. (B) Dorsal view shows calcification of brown adipose tissue in the neck (interscapular) and around the kidneys (arrowheads). (C) Ventral view shows calcified lesions in brown adipose tissue in the axillae and in the testes (arrowheads), and in the spleen and pancreas (arrowheads in D)

\section{Figure 3. Calcified lesions within the vasculature}

Von Kossa staining for mineral of paraffin sections of kidney $(A, B)$, brown adipose tissue (C, D) and pancreas (E) from a 52-week-old female D2,Ahsg-/- mouse. Mineral deposits stain black (also arrow), where calcified lesions occur frequently within arterioles, partially obstructing the lumen of these vessels. Hematoxylin and Eosin staining of paraffin sections, here of brown adipose tissue (F-G), reveals strong staining of the mineral deposits, indicating also the presence of a protein rich matrix in these calcified lesions. Scale bars $200 \mu \mathrm{m}(F)$, $100 \mu \mathrm{m}(\mathrm{A}, \mathrm{C}-\mathrm{E})$ and $50 \mu \mathrm{m}(\mathrm{B}, \mathrm{G})$.

\section{Figure 4. Electron micrographs of calcified lesions within small vessels}

Transmission electron micrographs of calcified lesions in brown adipose tissue from a 2week-old D2,Ahsg-/- mouse. Increasing magnifications (A-C) and additional micrographs (D$\mathrm{F}$ ) of lumenal mineral detected within small blood vessels. rbc, red blood cell; bv, blood vessel wall; ti, tunica intima; tm, tunica media; te, tunica externa; min, mineral; e, endothelium; vsmc, vascular smooth muscle cell. Scale bars: $10 \mu \mathrm{m}(\mathrm{A}, \mathrm{B}) ; 2 \mu \mathrm{m}(\mathrm{C}, \mathrm{D}, \mathrm{F}) ; 5$ $\mu \mathrm{m}(\mathrm{E})$.

\section{Figure 5. Mineral analysis of calcified lesions}

(A) Calcified lesion within an arteriole identified in a semi-thin plastic section stained with toluidine blue of brown adipose tissue from a 2-week-old D2,Ahsg-/- mouse. (B) Inset in (A) from the interior of the arteriole imaged from an adjacent thin section by TEM shows highly contrasted mineral density which were probed for mineral phase characterization. Circled areas show a calcium-phosphate mineral phase of poorly crystalline hydroxyapatite as 
determined by diffraction maxima obtained by X-ray diffraction and selected-area electron diffraction (C), and by energy-dispersive X-ray spectroscopy (D).

\section{Figure 6. Co-localization of early-stage calcified lesions and vascular markers}

Immunohistochemistry of cryosections prepared from lung $(A)$, myocardium (B, D) and brown adipose tissue $(C)$ of $D 2, A h s g-/-$ mice. Calcified lesions (arrows) stain positive for endogenous mineral-binding OPN (A, B, D) at sites also demarcated by CD31 (green), an endothelial cell marker (A, B) but not by Lyve-1 (green) a lymph-duct cell marker (D). Injected exogenous fetuin-A binds to mineral in calcified lesions and is readily detected using fetuin-A antibody (C). Even at early states of calcification (2 weeks of age, arrows in A and C), endogenous OPN and injected fetuin-A both demarcate small calcified lesions with high sensitivity (such small lesions are not detected in routine histology and computed tomography) surrounded by CD31-positive endothelial cells. Scale bars equal $50 \mu \mathrm{m}$.

\section{Figure 7. Samples as prepared for proteomic analysis of calcified lesions}

Calcified lesions as well as noncalcified adjacent tissue samples from skin and heart were dissected from D2,Ahsg-/- mice showing severe ectopic calcification. Proteins were extracted using SDS sample buffer containing EDTA (to dissolve mineral and release bound proteins) and homogenized using a mixer mill. (A-C) Nodular calcified lesions in subcutaneous fat tissue of skin stained with Alizarin Red $(A)$ or not $(B, C)$. Similar nodules were scraped from interscapular brown adipose tissue (BAT) and dissected from myocardium. (D) SDS-PAGE of samples prepared from serum, intact noncalcified tissue and calcified lesions of skin, heart and brown adipose tissue. M, molecular-weight marker.

\section{Figure 8. Gene expression in 6-week-old DBA/2 wildtype and Ahsg-/- mice}

Volcano plot representation of gene expression in kidney $(A)$ and brown fat $(B)$ dissected from the region of the kidney pelvis. Differential gene expression between fetuin-A-deficient and wildtype mice is shown as log-ratio on the $x$-axis; negative values represent higher expression in D2,Ahsg-/- mice, and positive values represent higher expression in wildtype mice. The $y$-axis encodes the probability for differential regulation calculated by Bayesian statistics in the Limma package under Bioconductor. Each dot denotes a probe set, and probe sets with the highest probability score are depicted in blue, probe sets with highest logratio are depicted in red, and marked probe sets are labeled with the appropriate gene name. Slc15a2 = solute carrier family $15(\mathrm{H}+$ /peptide transporter $)$, member 2 ; Pdxdc1 = pyridoxaldependent decarboxylase domain containing 1; Serpina6 = serine (or cysteine) peptidase inhibitor, clade A, member 6; Rpl17 = ribosomal protein L17; Ahsg = alpha-2-HSglycoprotein; Comt1 = catechol-O-methyltransferase 1; Gramd3 = GRAM domain containing 3; Akr1c18 = aldo-keto reductase family 1, member C18; Mup1 = major urinary protein 1; Mup3 = major urinary protein 3; Akr1c14 = aldo-keto reductase family 1, member C14; Gata3 = GATA binding protein 3; Foxa1 = forkhead box A1; Foxq1 = forkhead box Q1; Clca2 = chloride channel accessory 2; Sh3gl2 = SH3-domain GRB2-like 2; Klf5 = Kruppel-like factor 5 (intestinal); Mmp12 = matrix metallopeptidase 12; Mal = myelin and lymphocyte protein, $\mathrm{T}$ cell differentiation protein; 1110032A04Rik = RIKEN cDNA 1110032A04 gene; Sprr1a = small proline-rich protein $1 \mathrm{~A} ;$ Sprr2a $=$ small proline-rich protein $2 \mathrm{~A} ; \mathrm{Tmprss} 2=$ transmembrane protease, serine 2; Spp1 = secreted phosphoprotein 1; Pef1 = penta-EF hand domain containing 1 ; Cybrd $1=$ cytochrome $\mathrm{b}$ reductase 1 ; Kap $=$ kidney androgen regulated protein. 


\section{Supplemental Figure S1}

Nodular calcified lesions and reduced cardiac output in fetuin-A deficient DBA/2 mice. In unstained tissues, the nodular calcified lesions appear off-whitish, semi-transparent granules of sub-millimeter size. Nodules can be harvested mechanically by scraping of (A) brown adipose tissue in the neck, or from the subcutaneous fat layer of the skin (see maintext Figure 6 A-C). Nodules are present in the kidney fat pads (B), but not the kidney pelvis, of 6-week-old a D2,Ahsg-/- mice, ventricular wall and the atrium (C), lung tissue (D), spleen $(E)$, pancreas $(F)$, 16-week old kidney pelvis $(G)$, and ovaries $(H)$. J, Echocardiography showed that cardiac output was reduced in fetuin-A deficient DBA/2 mice compared to wildtype mice at all ages measured.

\section{Supplemental Figure S2}

Early- and late-stage calcification. Representative von Kossa staining for mineral in paraffin sections of kidney (A) and brown adipose tissue (B) from a 6-week-old D2,Ahsg-/mouse. Calcified lesions, indicated by black staining (arrows) can be observed in brown adipose tissue but not in the kidney parenchyma, reflecting the different calcification state of both tissues. Scale bars $200 \mu \mathrm{m}$.

\section{Supplemental Figure S3}

Innate immunity marker expression within calcified lesions. Paraffin sections of 11week-old D2,Ahsg-/- mice were prepared from myocardium (A-F) or lung (G-I) tissue. Sections were stained with antibodies against the macrophage surface marker $F 4 / 80(A, B$, $\mathrm{G})$, neutrophil myeloperoxidase $(\mathrm{C}, \mathrm{D}, \mathrm{H})$ and the monocyte/granulocyte marker $\mathrm{Ly}-6 \mathrm{G}$ and Ly-6C (Gr-1). Scale bars $50 \mu \mathrm{m}$.

\section{Supplemental Movie 1}

Post-mortem computed tomography showing ectopic calcification in the heart of a D2,Ahsg-/mouse at 16 weeks of age.

\section{Supplemental Movie 2}

Post-mortem computed tomography showing ectopic calcification in the lung from a D2,Ahsg-/- mouse at 16 weeks of age.

\section{Supplemental Movie 3}

Post-mortem computed tomography of a kidney dissected from a D2,Ahsg -/- mice at age 16weeks. Spherical mineralized lesions are detected in the kidney cortex. Note that adipose tissue localized in the kidney pelvis region is completely replaced by electron dense calcified lesions.

\section{Supplemental Movie 4}

Post-mortem computed tomography showing ectopic calcification of testis from a D2,Ahsg-/mouse at 16 weeks of age. 


\section{Supplemental Movie 5}

Post-mortem computed tomography showing ectopic calcification of skin from a D2,Ahsg-/mouse at 16 weeks of age.

\section{Supplemental Movie 6}

Post-mortem computed tomography showing ectopic calcification of the spleen from a D2,Ahsg-/- mouse at 16 weeks of age.

\section{Supplemental Movie 7}

Post-mortem computed tomography showing ectopic calcification of pancreas from a D2,Ahsg-/- mouse at 16 weeks of age. 
Table 1. Pathways associated with proteins contained in brown adipose tissue calcified lesions.

\begin{tabular}{|c|c|c|}
\hline pathway description & observed proteins & p-value \\
\hline Complement and coagulation cascades & 22 & $<0.001$ \\
\hline Metabolic pathways & 61 & $<0.001$ \\
\hline Microbial metabolism in diverse environments & 23 & $<0.001$ \\
\hline Carbon metabolism & 19 & $<0.001$ \\
\hline Ribosome & 20 & $<0.001$ \\
\hline Pyruvate metabolism & 13 & $<0.001$ \\
\hline Staphylococcus aureus infection & 12 & $<0.001$ \\
\hline Propanoate metabolism & 10 & $<0.001$ \\
\hline Systemic lupus erythematosus & 14 & $<0.001$ \\
\hline Citrate cycle (TCA cycle) & 9 & $<0.001$ \\
\hline Phagosome & 17 & $<0.001$ \\
\hline Prion diseases & 8 & $<0.001$ \\
\hline Parkinson s disease & 14 & $<0.001$ \\
\hline Biosynthesis of amino acids & 10 & $<0.001$ \\
\hline Valine, leucine and isoleucine degradation & 8 & $<0.001$ \\
\hline ECM-receptor interaction & 10 & $<0.001$ \\
\hline Glyoxylate and dicarboxylate metabolism & 6 & $<0.001$ \\
\hline Protein processing in endoplasmic reticulum & 13 & $<0.001$ \\
\hline Amoebiasis & 11 & $<0.001$ \\
\hline Nitrogen metabolism & 5 & $<0.001$ \\
\hline Huntington s disease & 13 & $<0.001$ \\
\hline Cysteine and methionine metabolism & 6 & $<0.001$ \\
\hline Legionellosis & 7 & 0.001 \\
\hline Focal adhesion & 13 & 0.001 \\
\hline Oxidative phosphorylation & 10 & 0.001 \\
\hline PI3K-Akt signaling pathway & 17 & 0.001 \\
\hline Alzheimer s disease & 11 & 0.001 \\
\hline Pentose phosphate pathway & 5 & 0.001 \\
\hline Fatty acid metabolism & 6 & 0.002 \\
\hline Antigen processing and presentation & 7 & 0.002 \\
\hline Pentose and glucuronate interconversions & 5 & 0.003 \\
\hline Fructose and mannose metabolism & 5 & 0.003 \\
\hline Spliceosome & 9 & 0.003 \\
\hline Glycerolipid metabolism & 6 & 0.003 \\
\hline Proximal tubule bicarbonate reclamation & 4 & 0.004 \\
\hline
\end{tabular}




\begin{tabular}{lll} 
Epstein-Barr virus infection & 11 & 0.005 \\
Pertussis & 6 & 0.010 \\
AMPK signaling pathway & 8 & 0.011 \\
Proteoglycans in cancer & 11 & 0.011 \\
Cardiac muscle contraction & 6 & 0.013 \\
Chagas disease (American trypanosomiasis) & 7 & 0.013 \\
PPAR signaling pathway & 6 & 0.015 \\
Galactose metabolism & 4 & 0.015 \\
Peroxisome & 6 & 0.017 \\
Arginine and proline metabolism & 5 & 0.018 \\
Toxoplasmosis & 7 & 0.019 \\
2-Oxocarboxylic acid metabolism & 3 & 0.020 \\
Small cell lung cancer & 6 & 0.020 \\
Non-alcoholic fatty liver disease (NAFLD) & 8 & 0.023 \\
Glycolysis / Gluconeogenesis & 5 & 0.023 \\
Protein digestion and absorption & 6 & 0.024 \\
Tryptophan metabolism & 4 & 0.036 \\
Fatty acid degradation & 4 & 0.039 \\
Fatty acid elongation & 3 & 0.040 \\
Measles & 7 & 0.048 \\
\hline & &
\end{tabular}


Table 2. Pathways associated with proteins contained in skin calcified lesions.

\begin{tabular}{|c|c|c|}
\hline pathway description & observed proteins & $p$-value \\
\hline Phagosome & 31 & $<0.001$ \\
\hline Complement and coagulation cascades & 14 & $<0.001$ \\
\hline Staphylococcus aureus infection & 12 & $<0.001$ \\
\hline Ribosome & 17 & $<0.001$ \\
\hline Systemic lupus erythematosus & 14 & $<0.001$ \\
\hline Lysosome & 14 & $<0.001$ \\
\hline Antigen processing and presentation & 11 & $<0.001$ \\
\hline Tuberculosis & 16 & $<0.001$ \\
\hline Amoebiasis & 13 & $<0.001$ \\
\hline Protein digestion and absorption & 11 & $<0.001$ \\
\hline Proteasome & 8 & $<0.001$ \\
\hline Protein processing in endoplasmic reticulum & 13 & $<0.001$ \\
\hline ECM-receptor interaction & 9 & 0.001 \\
\hline Leukocyte transendothelial migration & 10 & 0.002 \\
\hline Focal adhesion & 13 & 0.003 \\
\hline Rheumatoid arthritis & 8 & 0.003 \\
\hline Regulation of actin cytoskeleton & 13 & 0.004 \\
\hline Spliceosome & 9 & 0.010 \\
\hline PPAR signaling pathway & 7 & 0.010 \\
\hline Proximal tubule bicarbonate reclamation & 4 & 0.010 \\
\hline Legionellosis & 6 & 0.010 \\
\hline Carbon metabolism & 8 & 0.013 \\
\hline Pertussis & 6 & 0.028 \\
\hline Citrate cycle (TCA cycle) & 4 & 0.031 \\
\hline Oxidative phosphorylation & 8 & 0.035 \\
\hline Pancreatic secretion & 7 & 0.035 \\
\hline Nitrogen metabolism & 3 & 0.040 \\
\hline Prion diseases & 4 & 0.042 \\
\hline Hematopoietic cell lineage & 6 & 0.045 \\
\hline Microbial metabolism in diverse environments & 9 & 0.048 \\
\hline
\end{tabular}


Table 3. Pathways associated with proteins contained in heart calcified lesions.

\begin{tabular}{|c|c|c|}
\hline pathway description & observed proteins & p-value \\
\hline Complement and coagulation cascades & 20 & $<0.001$ \\
\hline Proteasome & 8 & $<0.001$ \\
\hline Citrate cycle (TCA cycle) & 7 & $<0.001$ \\
\hline Prion diseases & 7 & $<0.001$ \\
\hline Carbon metabolism & 10 & $<0.001$ \\
\hline Amoebiasis & 10 & $<0.001$ \\
\hline Hypertrophic cardiomyopathy (HCM) & 8 & $<0.001$ \\
\hline ECM-receptor interaction & 8 & $<0.001$ \\
\hline Dilated cardiomyopathy & 8 & $<0.001$ \\
\hline Metabolic pathways & 26 & $<0.001$ \\
\hline Staphylococcus aureus infection & 6 & $<0.001$ \\
\hline Alzheimer s disease & 9 & $<0.001$ \\
\hline Microbial metabolism in diverse environments & 9 & $<0.001$ \\
\hline Systemic lupus erythematosus & 7 & $<0.001$ \\
\hline 2-Oxocarboxylic acid metabolism & 4 & $<0.001$ \\
\hline PI3K-Akt signaling pathway & 12 & $<0.001$ \\
\hline Biosynthesis of amino acids & 6 & $<0.001$ \\
\hline Cardiac muscle contraction & 6 & $<0.001$ \\
\hline PPAR signaling pathway & 6 & $<0.001$ \\
\hline Huntington s disease & 8 & 0.001 \\
\hline Parkinson s disease & 7 & 0.001 \\
\hline Focal adhesion & 8 & 0.002 \\
\hline Phagosome & 7 & 0.003 \\
\hline Arrhythmogenic right ventricular cardiomyopathy (ARVC) & 5 & 0.003 \\
\hline Fatty acid degradation & 4 & 0.004 \\
\hline Peroxisome & 5 & 0.004 \\
\hline Oxidative phosphorylation & 6 & 0.005 \\
\hline Fatty acid metabolism & 4 & 0.006 \\
\hline Epstein-Barr virus infection & 7 & 0.008 \\
\hline Proteoglycans in cancer & 7 & 0.014 \\
\hline Antigen processing and presentation & 4 & 0.021 \\
\hline Viral carcinogenesis & 6 & 0.035 \\
\hline Small cell lung cancer & 4 & 0.035 \\
\hline Adrenergic signaling in cardiomyocytes & 5 & 0.038 \\
\hline Protein digestion and absorption & 4 & 0.039 \\
\hline
\end{tabular}


Table 4. Differential expression in kidneys of 5-week-old D2,Ahsg-/- mice.

\begin{tabular}{llll} 
probe set & symbol & p-value & log-ratio \\
\hline induced genes & & & \\
solute carrier family 15 (H+/peptide transporter), member 2 & Slc15a2 & $<0.001$ & -3.821 \\
solute carrier family 15 (H+/peptide transporter), member 2 & Slc15a2 & $<0.001$ & -2.624 \\
pyridoxal-dependent decarboxylase domain containing 1 & Pdxdc1 & $<0.001$ & -2.532 \\
angiotensin I converting enzyme (peptidyl-dipeptidase A) 2 & Ace2 & 0.030 & -1.117 \\
ubiquitin specific peptidase 1 & Usp1 & 0.011 & -1.079 \\
pyridoxal-dependent decarboxylase domain containing 1 & Pdxdc1 & 0.038 & -0.929 \\
sulfotransferase family 3A, member 1 & Sult3a1 & 0.049 & -0.913 \\
repressed genes & & & \\
pyridoxal-dependent decarboxylase domain containing 1 & Pdxdc1 & $<0.001$ & 3.849 \\
major urinary protein 1 & Mup1 & $<0.001$ & 3.601 \\
aldo-keto reductase family 1, member C18 & Akr1c18 & 0.001 & 2.625 \\
catechol-O-methyltransferase 1 & Comt1 & $<0.001$ & 2.141 \\
GRAM domain containing 3 & Gramd3 & $<0.001$ & 2.109 \\
alpha-2-HS-glycoprotein & Ahsg & $<0.001$ & 1.973 \\
ribosomal protein L17 & Rpl17 & $<0.001$ & 1.854 \\
GRAM domain containing 3 & Gramd3 & $<0.001$ & 1.517 \\
ring finger protein 41 & Rnf41 & 0.012 & 1.022 \\
\hline & & & \\
\hline & & &
\end{tabular}

The table shows probe sets, which were significantly ( $p$-value $<0.05$ ) differentially expressed in kidneys dissected from 5-week-old DBA/2 wildtype and fetuin-A deficient mice. Bayesian statistics was used for calculation of probabilities ( $p$-value) and log-ratio, negative log-ratio encode gene induction of the particular probe-set in fetuin-A deficient mice, positive values denote gene repression. Note that gene names are given for each probe set, double entries may occur in case of genes which are represented by several probe sets encoding different regions or splice variants of the gene. 
Table 5. Differential expression in adipose tissue of 6-week-old D2,Ahsg-/- mice.

\begin{tabular}{|c|c|c|c|}
\hline probe set & symbol & p-value & log-ratio \\
\hline \multicolumn{4}{|l|}{ induced genes } \\
\hline RIKEN cDNA 1110032A04 gene & 1110032A04Rik & 0.004 & -6.977 \\
\hline small proline-rich protein $1 \mathrm{~A}$ & Sprr1a & 0.005 & -6.021 \\
\hline small proline-rich protein $2 \mathrm{~A}$ & Sprr2a & 0.005 & -5.495 \\
\hline small proline-rich protein $2 \mathrm{~A}$ & Sprr2a & 0.009 & -4.683 \\
\hline RIKEN cDNA 1110032A04 gene & 1110032A04Rik & 0.003 & -4.369 \\
\hline myelin and lymphocyte protein, T-cell differentiation protein & Mal & 0.001 & -4.316 \\
\hline matrix metallopeptidase 12 & Mmp12 & 0.001 & -4.315 \\
\hline transmembrane protease, serine 2 & Tmprss2 & 0.008 & -4.157 \\
\hline secreted phosphoprotein 1 & Spp1 & 0.024 & -4.116 \\
\hline uroplakin $3 \mathrm{~A}$ & Upk3a & 0.014 & -3.949 \\
\hline lymphocyte antigen 6 complex, locus D & Ly6d & 0.002 & -3.845 \\
\hline sorting nexin 31 & Snx31 & 0.008 & -3.728 \\
\hline forkhead box A1 & Foxa1 & 0.001 & -3.628 \\
\hline myelin protein zero & Mpz & 0.001 & -3.525 \\
\hline Purkinje cell protein 4 & Pcp4 & 0.001 & -3.493 \\
\hline prostate stem cell antigen & Psca & 0.008 & -3.436 \\
\hline carnitine palmitoyltransferase $1 \mathrm{~b}$, muscle & Cpt1b & 0.006 & -3.390 \\
\hline WAP four-disulfide core domain 2 & Wfdc2 & 0.022 & -3.351 \\
\hline cadherin 1 & Cdh1 & 0.007 & -3.256 \\
\hline claudin 4 & Cldn4 & 0.002 & -3.185 \\
\hline pyridoxal-dependent decarboxylase domain containing 1 & Pdxdc1 & $<0.001$ & -3.159 \\
\hline myelin basic protein & Mbp & 0.001 & -3.148 \\
\hline forkhead box Q1 & Foxq1 & 0.001 & -3.137 \\
\hline involucrin & $\mathrm{IVI}$ & 0.005 & -3.078 \\
\hline transmembrane protease, serine 2 & Tmprss2 & 0.016 & -3.063 \\
\hline FXYD domain-containing ion transport regulator 3 & Fxyd3 & 0.001 & -3.056 \\
\hline keratin 18 & Krt18 & 0.002 & -3.046 \\
\hline \multicolumn{4}{|l|}{ repressed genes } \\
\hline pyridoxal-dependent decarboxylase domain containing 1 & Pdxdc1 & $<0.001$ & 4.111 \\
\hline cytochrome $b$ reductase 1 & Cybrd1 & $<0.001$ & 3.119 \\
\hline penta-EF hand domain containing 1 & Pef1 & $<0.001$ & 3.108 \\
\hline
\end{tabular}

The table shows probe sets, which were significantly ( $p$-value $<0.05)$ differentially expressed in adipose tissue. Bayesian statistics was used for calculation of probabilities ( $p$-value) and log-ratio, negative log-ratio encode gene induction of the particular probe-set in fetuin-A 
deficient mice, positive values denote gene repression. The table shows most highly differentially regulated genes with a log-ratio above 3 . Note that gene names are given for each probe set, double entries may occur in case of genes which are represented by several probe sets encoding different regions or splice variants of the gene. 
Table 6. Pathway analysis of significant regulated genes in brown adipose tissue of D2,Ahsg-/- mice.

\begin{tabular}{lll} 
KEGG pathway & size & p-value \\
\hline Focal adhesion & 174 & 0.001 \\
ECM-receptor interaction & 74 & 0.004 \\
Cell cycle & 100 & 0.005 \\
p53 signaling pathway & 54 & 0.005 \\
Small cell lung cancer & 79 & 0.006 \\
$\begin{array}{l}\text { Selenoamino acid metabolism } \\
\text { Aminophosphonate }\end{array}$ & 25 & 0.015 \\
$\begin{array}{l}\text { metabolism } \\
\text { Cell adhesion molecules }\end{array}$ & 13 & 0.03 \\
(CAMs) & 115 & 0.034 \\
Notch signaling pathway & 37 & 0.043 \\
Bladder cancer & 37 & 0.043 \\
\hline
\end{tabular}

Differentially expressed probe sets in adipose tissue were tested of over-representation of KEGG gene sets. For each gene set the name of the pathway and the corresponding size is given. The probability of overrepresentation of the gene set is assumed by the $p$-value. 

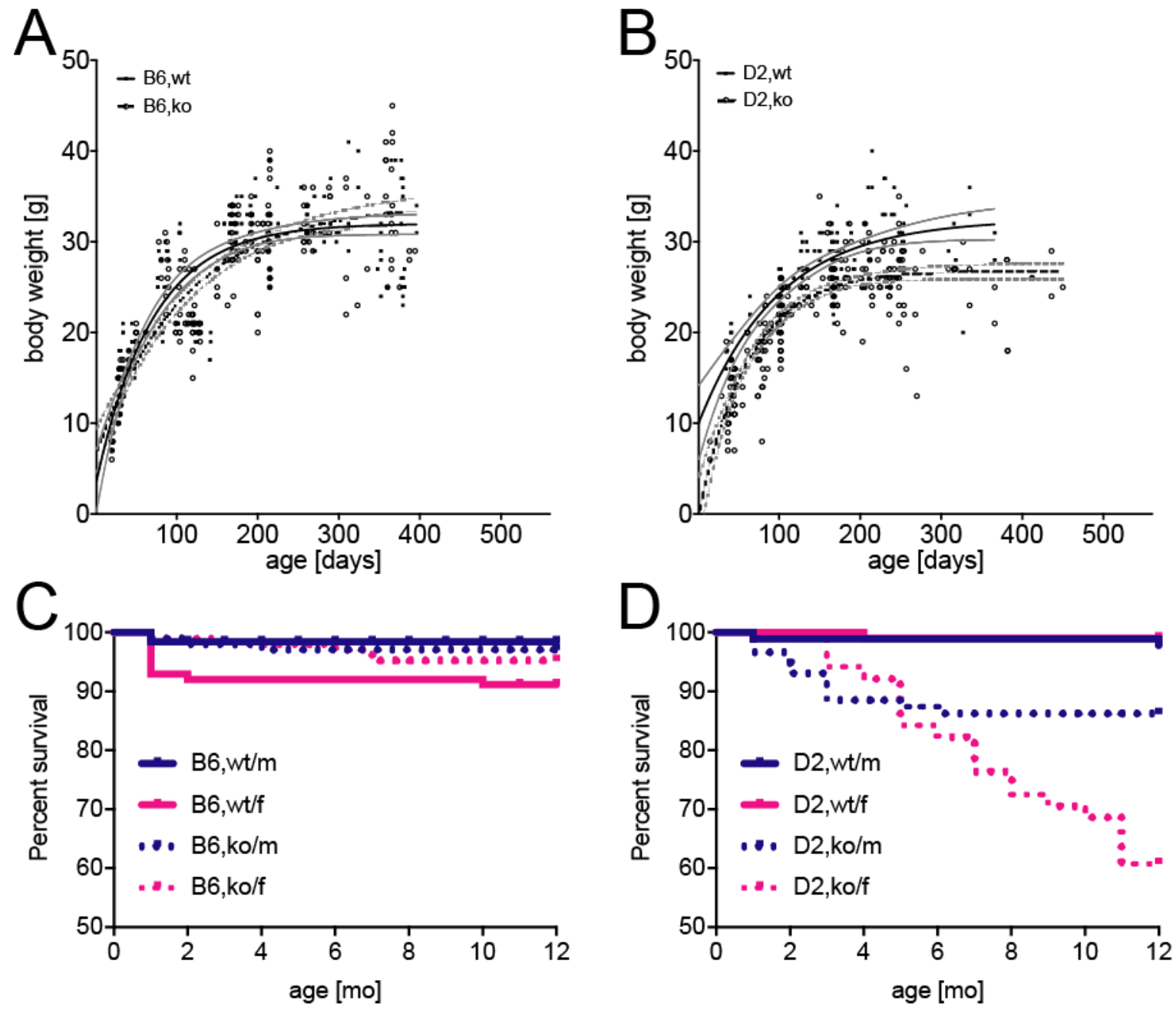

Figure 1 Impaired growth and premature death in fetuin-A deficient DBA/2 mice.

$A, B$, Random selected mice from the colony were weighed each at the day they were sacrificed for imaging or tissue harvest. Note that overall, C57BL/6 wildtype (B6,wt) $(n=213)$ and fetuin-A deficient mice $(B 6, k o)(n=205)$, and DBA/2 wildtype mice (D2,wt) $(n=138)$ all attained a maximum weight of $30 \pm 5$ gram while $D 2, k o$ mice $(n=244)$ weighed in at roughly five $g$ lighter. The $95 \%$ confidence intervals of body weights are plotted as grey lines flanking the black fitted weight curves in each case. Outlier D2,ko mice with less than half normal body weight invariably were the most calcified upon autopsy (figure 6 and suppl figure 1). C, $\mathrm{D}$, The 12-month survival rate in B6,wt, B6,ko and D2,wt mice was higher than $90 \%$ regardless of sex and genetic background. In contrast the survival rates in D2,ko mice were reduced at $86 \%$ in male and $61 \%$ in female mice. 

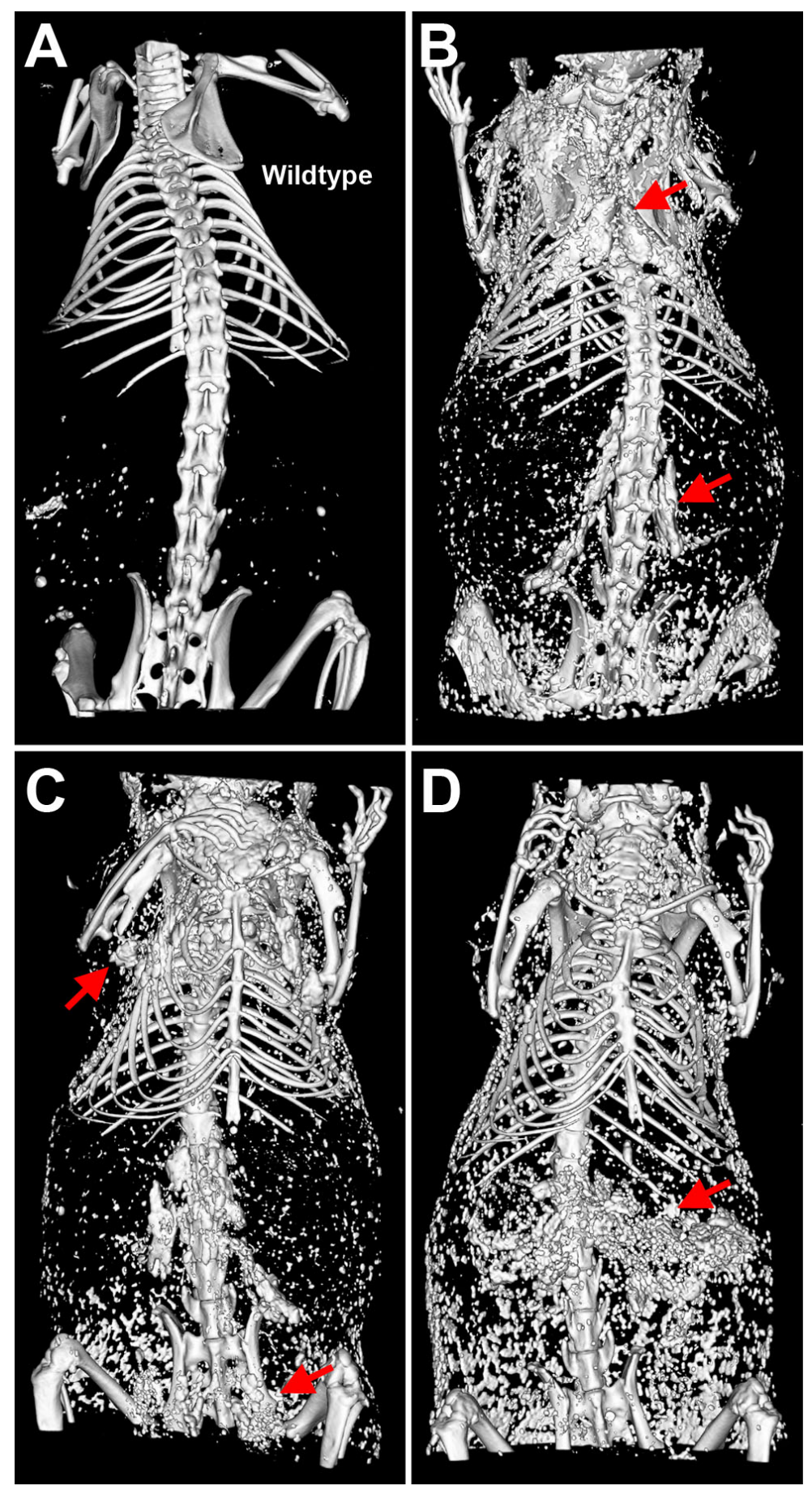

Figure 2. Typical examples of adult calcified D2,Ahsg-/- mice

Computed tomography of $(A)$ a male wildtype control mouse at 30 weeks of age, and (B-D) $\mathrm{D} 2$, Ahsg -/- mice at 20 weeks $(\mathrm{B}, \mathrm{C})$ or 35 weeks (D) of age. (A) Mineral in the skeleton, and food-derived mineral speckling in the GI tract. (B) Dorsal view shows calcification of brown adipose tissue in the neck (interscapular) and around the kidneys (arrowheads). (C) Ventral view shows calcified lesions in brown adipose tissue in the axillae and in the testes (arrowheads), and in the spleen and pancreas (arrowheads in D) 


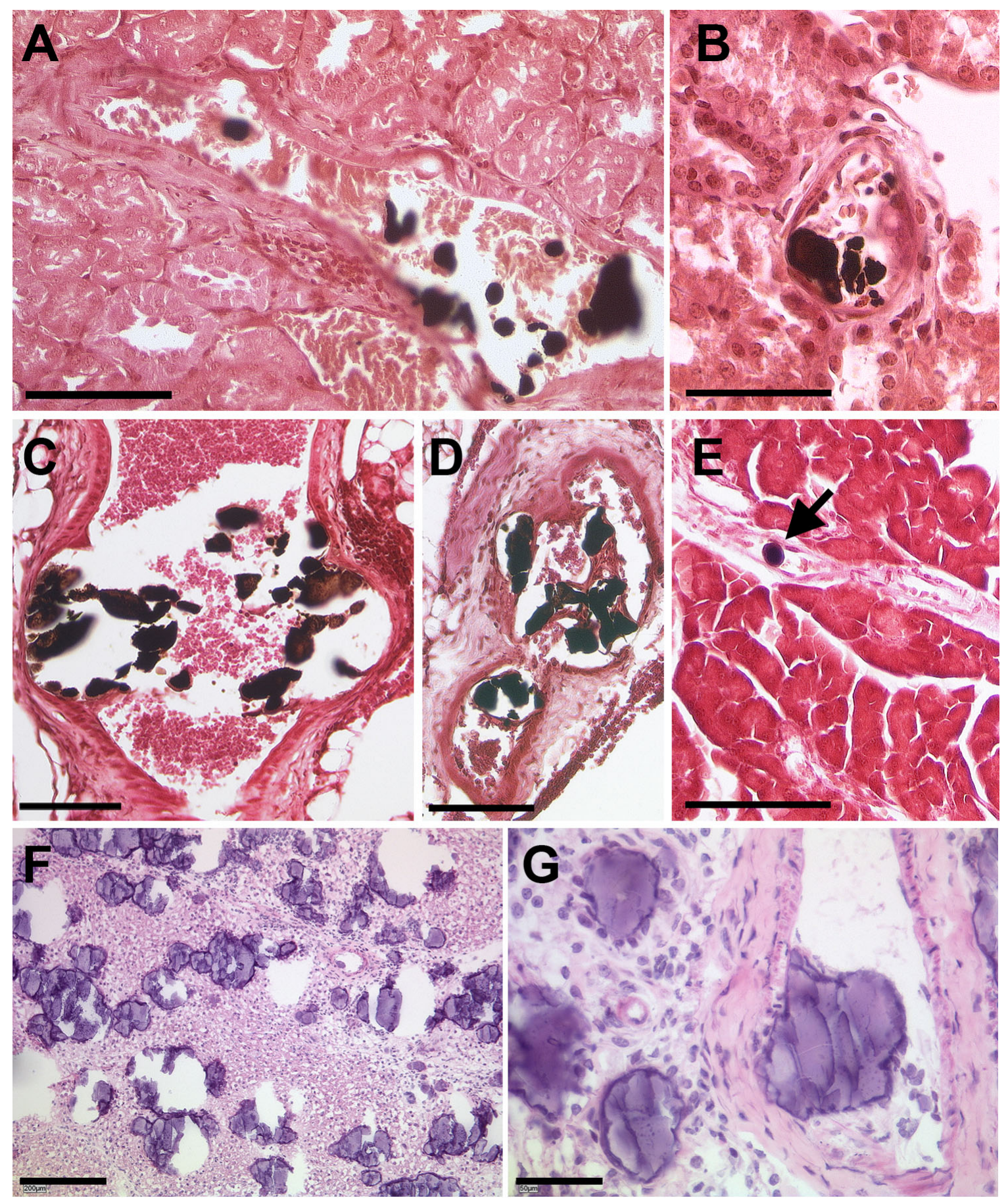

Figure 3. Calcified lesions within the vasculature

Von Kossa staining for mineral of paraffin sections of kidney $(A, B)$, brown adipose tissue (C, $D)$ and pancreas (E) from a 52-week-old female D2,Ahsg-/- mouse. Mineral deposits stain black (also arrow), where calcified lesions occur frequently within arterioles, partially obstructing the lumen of these vessels. Hematoxylin and Eosin staining of paraffin sections, here of brown adipose tissue ( $F-G)$, reveals strong staining of the mineral deposits, indicating also the presence of a protein rich matrix in these calcified lesions. Scale bars $200 \mu \mathrm{m}(\mathrm{F})$, $100 \mu \mathrm{m}(\mathrm{A}, \mathrm{C}-\mathrm{E})$ and $50 \mu \mathrm{m}(\mathrm{B}, \mathrm{G})$. 

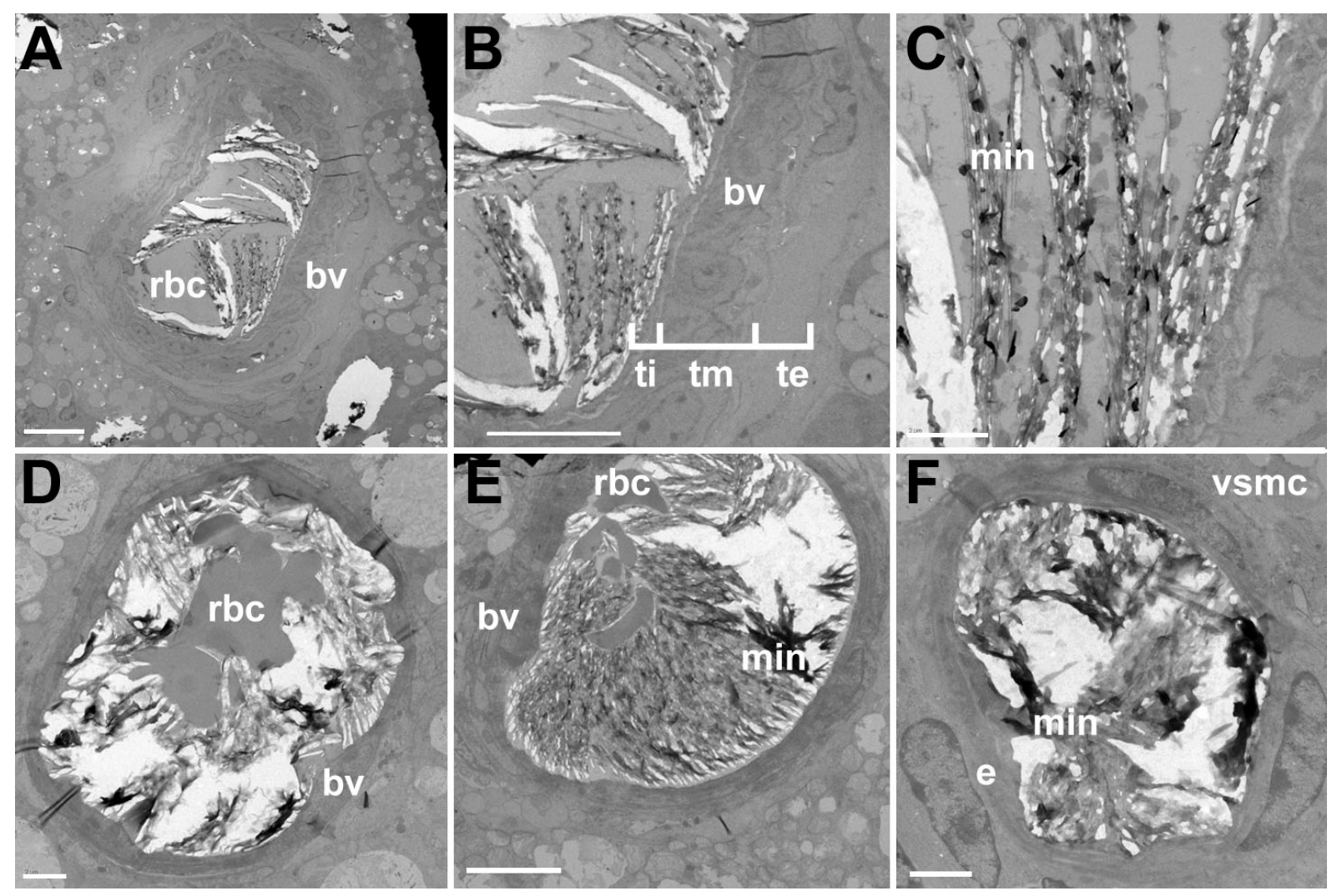

\section{Figure 4. Electron micrographs of calcified lesions within small vessels}

Transmission electron micrographs of calcified lesions in brown adipose tissue from a 2week-old D2,Ahsg-/- mouse. Increasing magnifications (A-C) and additional micrographs (DF) of lumenal mineral detected within small blood vessels. rbc, red blood cell; bv, blood vessel wall; ti, tunica intima; tm, tunica media; te, tunica externa; min, mineral; e, endothelium; vsmc, vascular smooth muscle cell. Scale bars: $10 \mu \mathrm{m}(\mathrm{A}, \mathrm{B}) ; 2 \mu \mathrm{m}(\mathrm{C}, \mathrm{D}, \mathrm{F}) ; 5$ $\mu \mathrm{m}(\mathrm{E})$. 

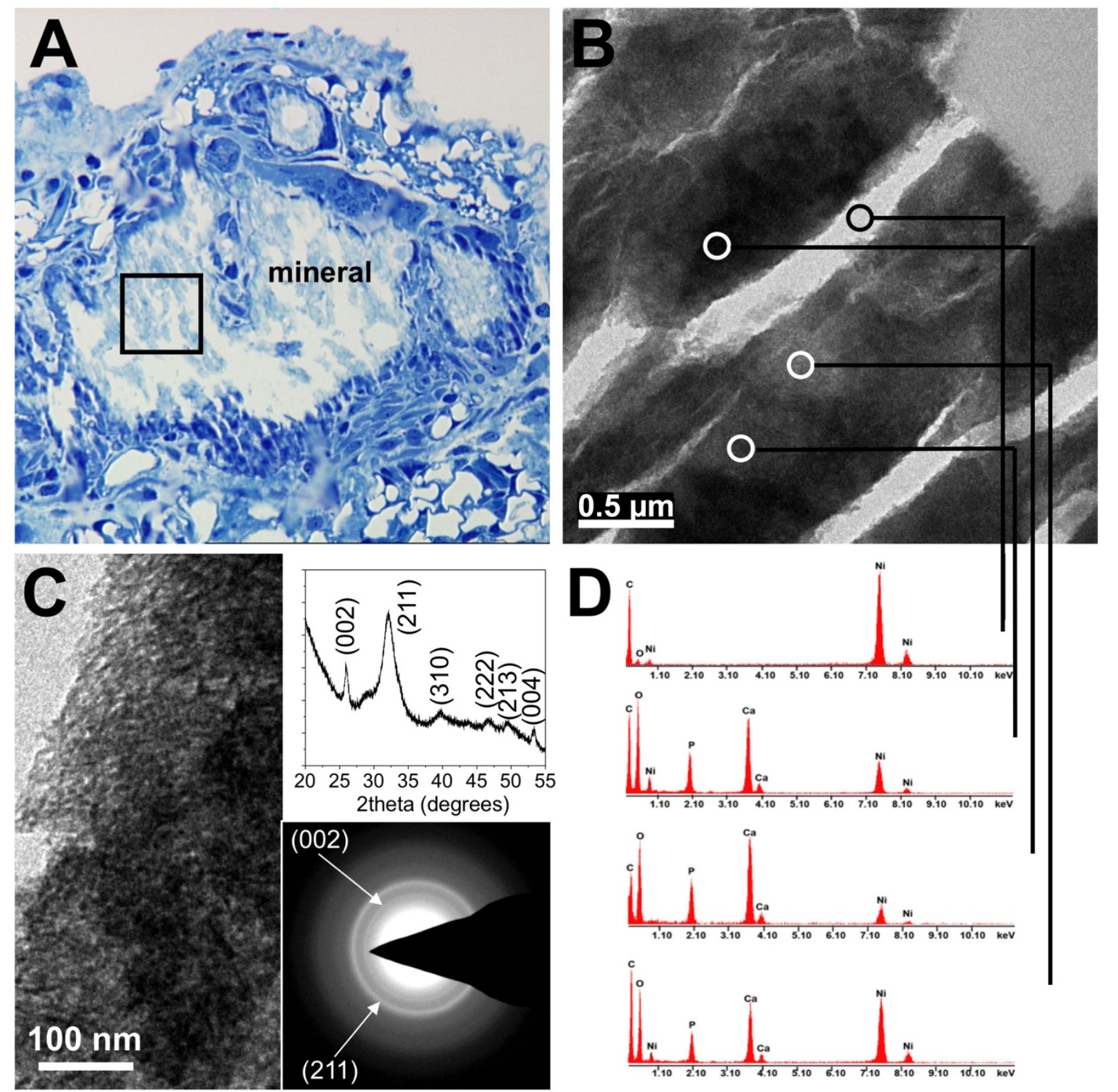

Figure 5. Mineral analysis of calcified lesions

(A) Calcified lesion within an arteriole identified in a semi-thin plastic section stained with toluidine blue of brown adipose tissue from a 2-week-old D2,Ahsg-/- mouse. (B) Inset in (A) from the interior of the arteriole imaged from an adjacent thin section by TEM shows highly contrasted mineral density which were probed for mineral phase characterization. Circled areas show a calcium-phosphate mineral phase of poorly crystalline hydroxyapatite as determined by diffraction maxima obtained by X-ray diffraction and selected-area electron diffraction (C), and by energy-dispersive X-ray spectroscopy (D). 

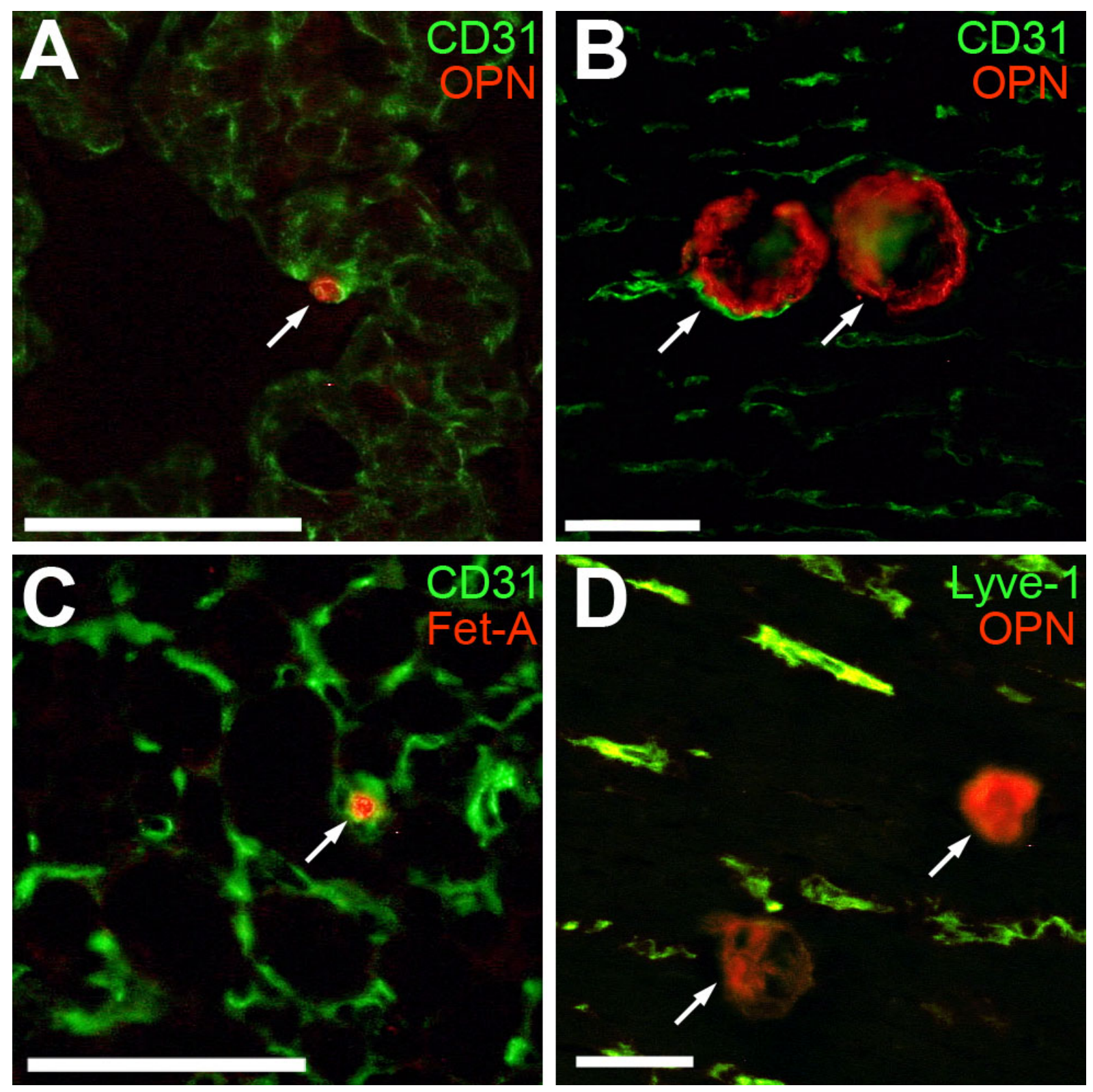

\section{Figure 6. Co-localization of early-stage calcified lesions and vascular markers}

Immunohistochemistry of cryosections prepared from lung $(A)$, myocardium $(B, D)$ and brown adipose tissue (C) of D2,Ahsg-/- mice. Calcified lesions (arrows) stain positive for endogenous mineral-binding OPN (A, B, D) at sites also demarcated by CD31 (green), an endothelial cell marker (A, B) but not by Lyve-1 (green) a lymph-duct cell marker (D). Injected exogenous fetuin-A binds to mineral in calcified lesions and is readily detected using fetuin-A antibody $(C)$. Even at early states of calcification (2 weeks of age, arrows in A and C), endogenous OPN and injected fetuin-A both demarcate small calcified lesions with high sensitivity (such small lesions are not detected in routine histology and computed tomography) surrounded by CD31-positive endothelial cells. Scale bars equal $50 \mu \mathrm{m}$. 


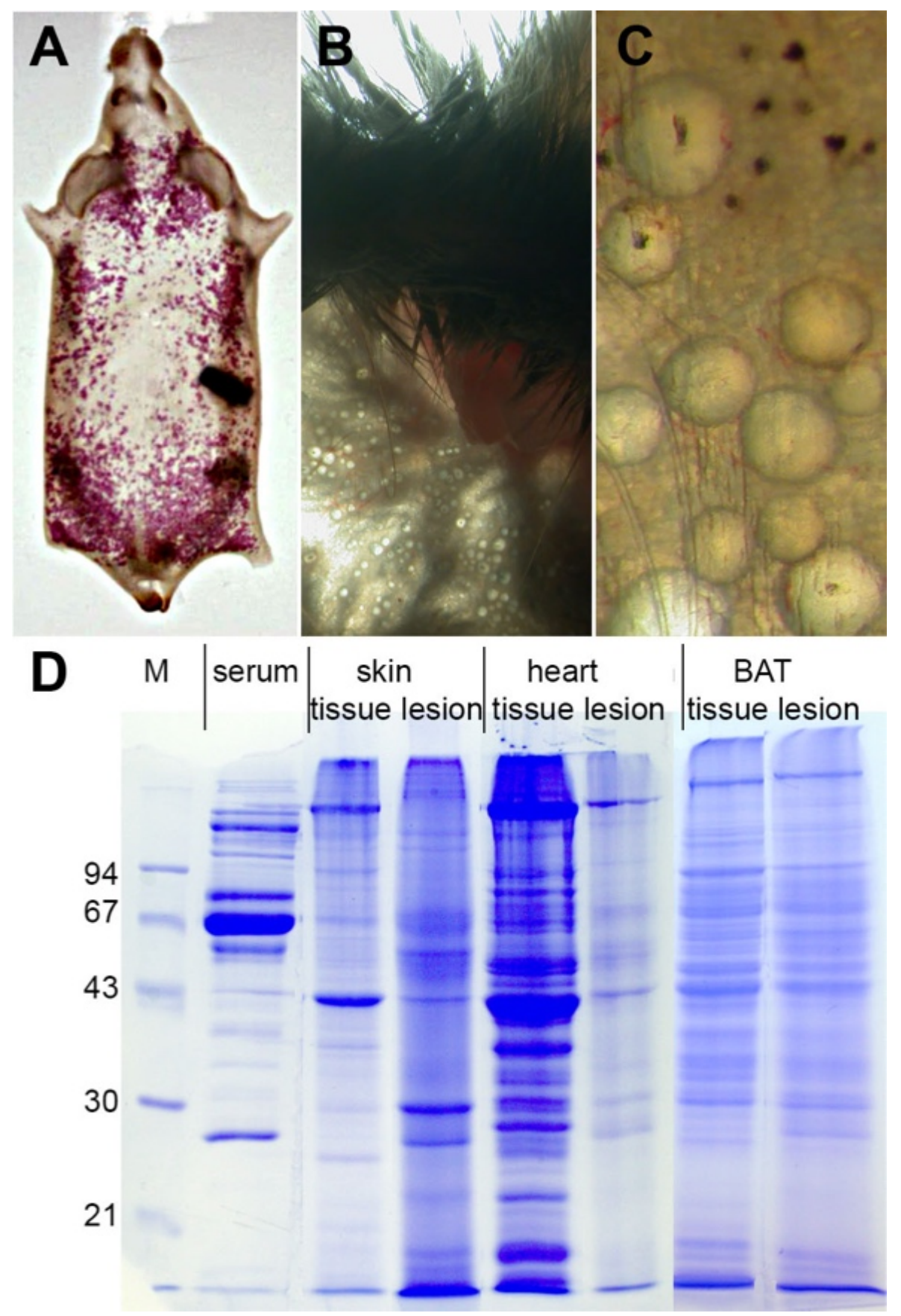

\section{Figure 7. Samples as prepared for proteomic analysis of calcified lesions}

Calcified lesions as well as noncalcified adjacent tissue samples from skin and heart were dissected from D2,Ahsg-/- mice showing severe ectopic calcification. Proteins were extracted using SDS sample buffer containing EDTA (to dissolve mineral and release bound proteins) and homogenized using a mixer mill. (A-C) Nodular calcified lesions in subcutaneous fat tissue of skin stained with Alizarin $\operatorname{Red}(A)$ or not $(B, C)$. Similar nodules were scraped from interscapular brown adipose tissue (BAT) and dissected from myocardium. (D) SDS-PAGE of samples prepared from serum, intact noncalcified tissue and calcified lesions of skin, heart and brown adipose tissue. $\mathrm{M}$, molecular-weight marker. 

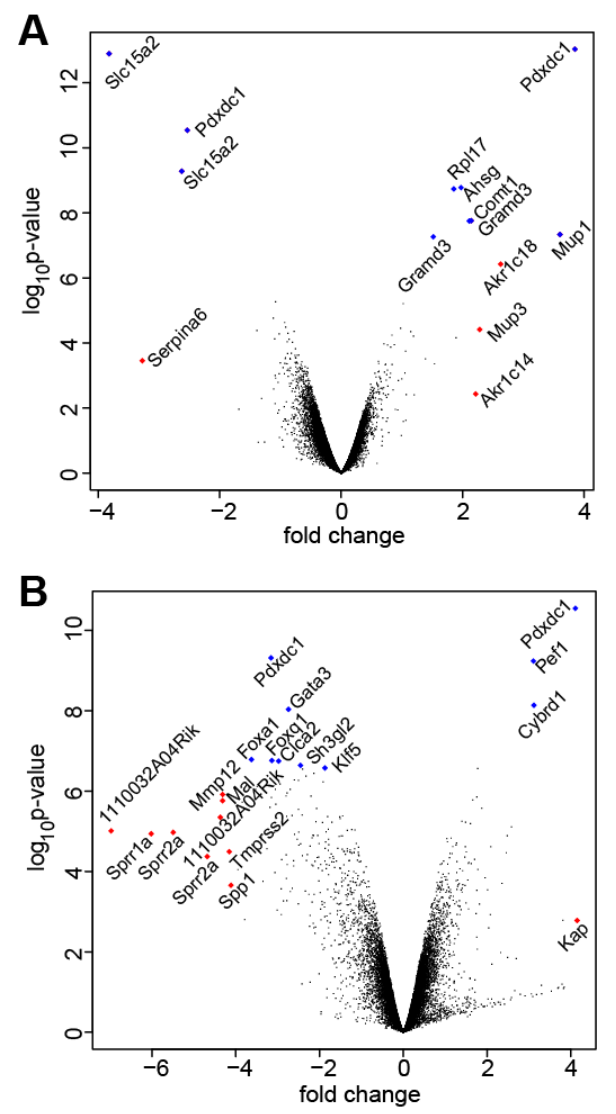

Figure 8. Gene expression in 6-week-old DBA/2 wildtype and Ahsg-/- mice

Volcano plot representation of gene expression in kidney $(A)$ and brown fat $(B)$ dissected from the region of the kidney pelvis. Differential gene expression between fetuin-A-deficient and wildtype mice is shown as log-ratio on the $\mathrm{x}$-axis; negative values represent higher expression in D2,Ahsg-/- mice, and positive values represent higher expression in wildtype mice. The $y$-axis encodes the probability for differential regulation calculated by Bayesian statistics in the Limma package under Bioconductor. Each dot denotes a probe set, and probe sets with the highest probability score are depicted in blue, probe sets with highest logratio are depicted in red, and marked probe sets are labeled with the appropriate gene name. Slc15a2 = solute carrier family $15(\mathrm{H}+$ /peptide transporter $)$, member 2 ; Pdxdc1 = pyridoxaldependent decarboxylase domain containing 1; Serpina6 = serine (or cysteine) peptidase inhibitor, clade A, member 6; Rpl17 = ribosomal protein L17; Ahsg = alpha-2-HSglycoprotein; Comt1 = catechol-O-methyltransferase 1; Gramd3 = GRAM domain containing 3; Akr1c18 = aldo-keto reductase family 1, member C18; Mup1 = major urinary protein 1; Mup3 = major urinary protein 3; Akr1c14 = aldo-keto reductase family 1, member C14; Gata3 = GATA binding protein 3; Foxa1 = forkhead box A1; Foxq1 = forkhead box Q1; Clca2 = chloride channel accessory 2; Sh3gl2 = SH3-domain GRB2-like 2; Klf5 = Kruppel-like factor 5 (intestinal); Mmp12 = matrix metallopeptidase 12; Mal = myelin and lymphocyte protein, Tcell differentiation protein; 1110032A04Rik = RIKEN cDNA 1110032A04 gene; Sprr1a = small proline-rich protein $1 \mathrm{~A} ;$ Sprr2a = small proline-rich protein $2 \mathrm{~A} ; \mathrm{Tmprss} 2=$ transmembrane protease, serine 2; Spp1 = secreted phosphoprotein 1; Pef1 = penta-EF hand domain containing 1 ; Cybrd1 = cytochrome $\mathrm{b}$ reductase 1 ; Kap = kidney androgen regulated protein. 

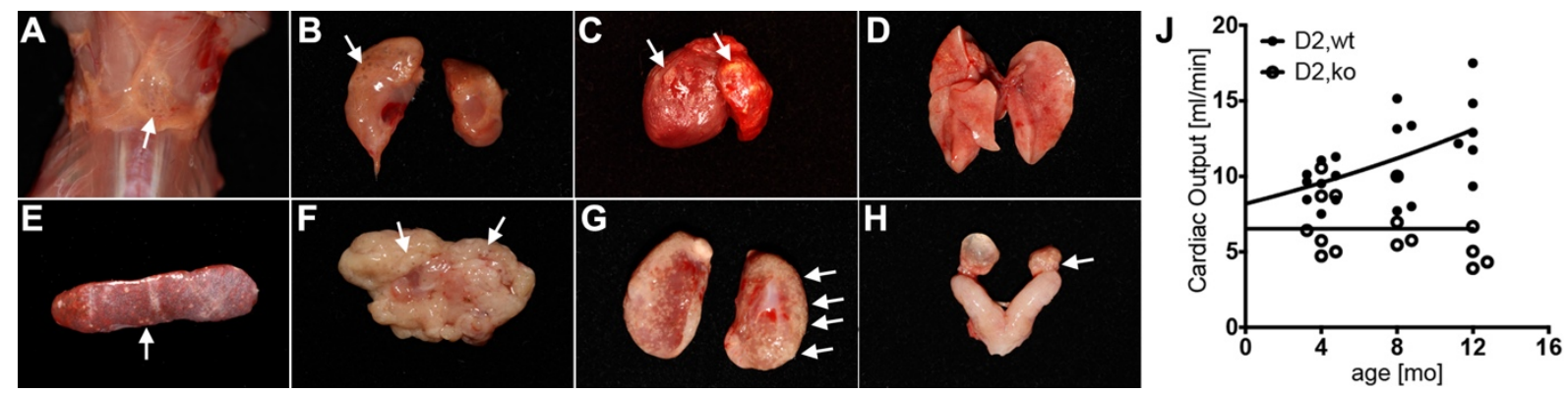

\section{Supplemental Figure $\mathbf{S 1}$}

Nodular calcified lesions and reduced cardiac output in fetuin-A deficient DBA/2 mice.

In unstained tissues, the nodular calcified lesions appear off-whitish, semi-transparent granules of sub-millimeter size. Nodules can be harvested mechanically by scraping of (A) brown adipose tissue in the neck, or from the subcutaneous fat layer of the skin (see maintext Figure $6 \mathrm{~A}-\mathrm{C}$ ). Nodules are present in the kidney fat pads (B), but not the kidney pelvis, of 6-week-old a D2,Ahsg-/- mice, ventricular wall and the atrium (C), lung tissue (D), spleen $(E)$, pancreas $(F)$, 16-week old kidney pelvis $(G)$, and ovaries $(H)$. J, Echocardiography showed that cardiac output was reduced in fetuin-A deficient DBA/2 mice compared to wildtype mice at all ages measured. 

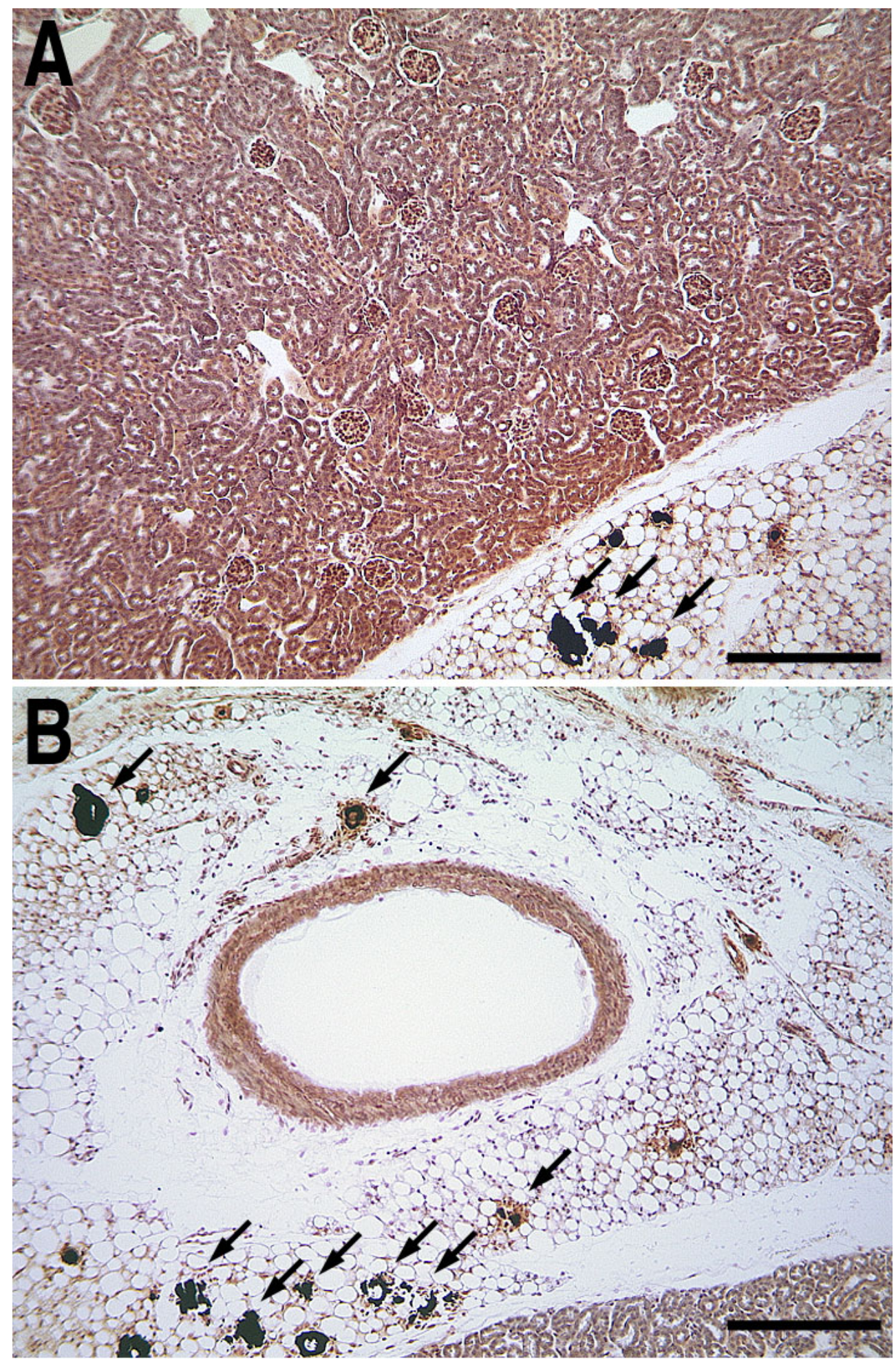

\section{Supplemental Figure S2}

Early- and late-stage calcification. Representative von Kossa staining for mineral in paraffin sections of kidney (A) and brown adipose tissue (B) from a 6-week-old D2,Ahsg-/mouse. Calcified lesions, indicated by black staining (arrows) can be observed in brown adipose tissue but not in the kidney parenchyma, reflecting the different calcification state of both tissues. Scale bars $200 \mu \mathrm{m}$. 


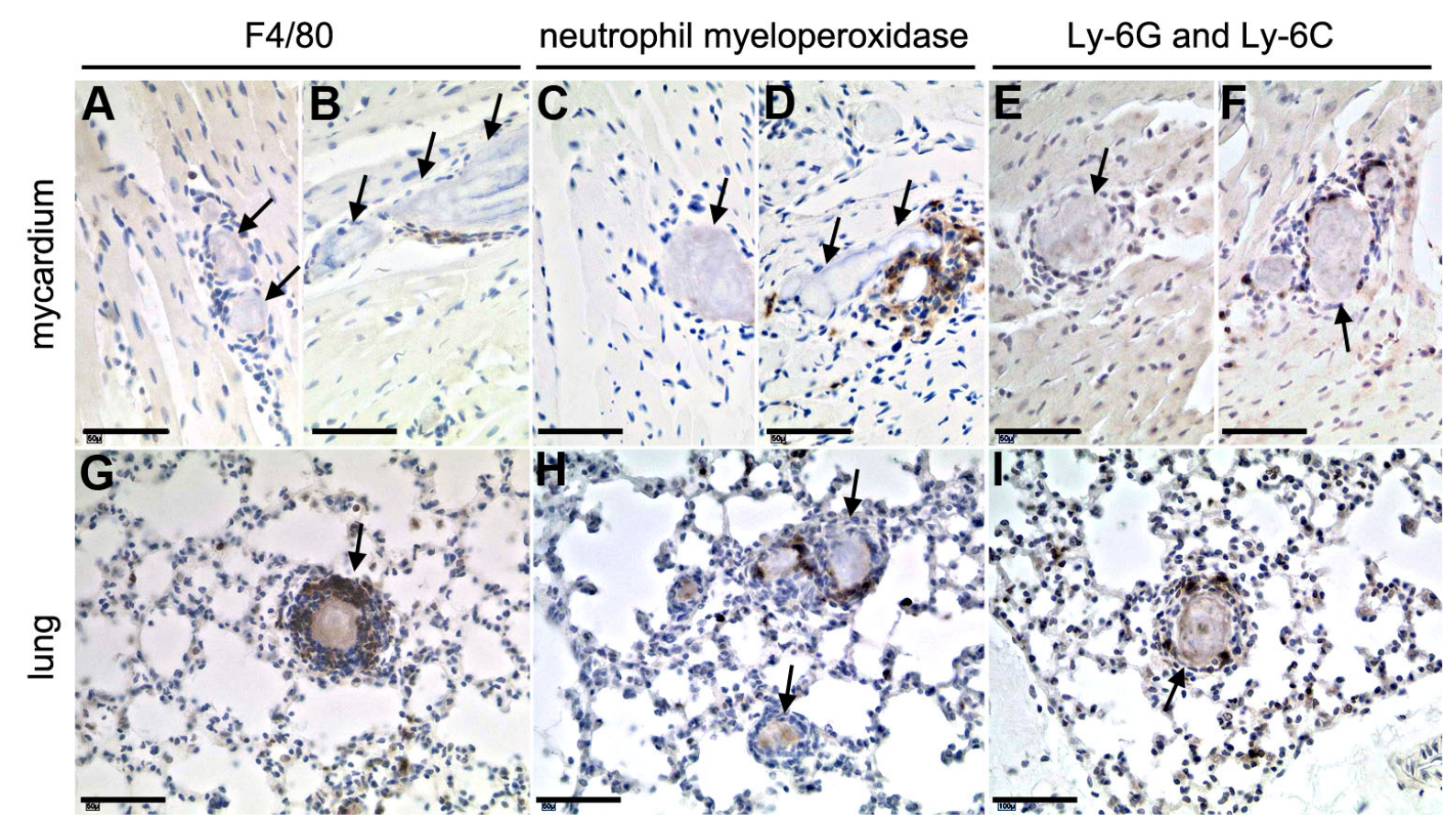

\section{Supplemental Figure S3}

Innate immunity marker expression within calcified lesions. Paraffin sections of 11week-old D2,Ahsg-/- mice were prepared from myocardium (A-F) or lung (G-I) tissue. Sections were stained with antibodies against the macrophage surface marker $F 4 / 80$ ( $A, B$, $\mathrm{G})$, neutrophil myeloperoxidase $(\mathrm{C}, \mathrm{D}, \mathrm{H})$ and the monocyte/granulocyte marker $\mathrm{Ly}-6 \mathrm{G}$ and Ly-6C (Gr-1). Scale bars $50 \mu \mathrm{m}$. 


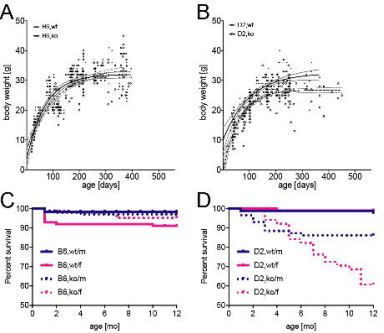




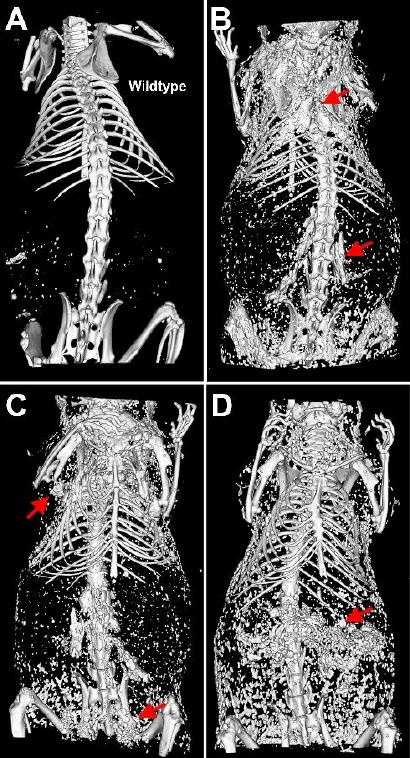




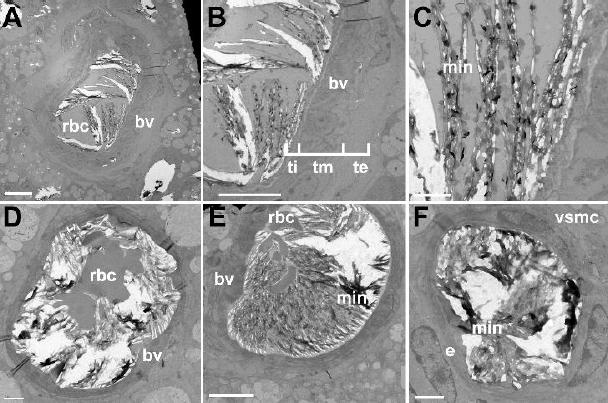




\section{A}

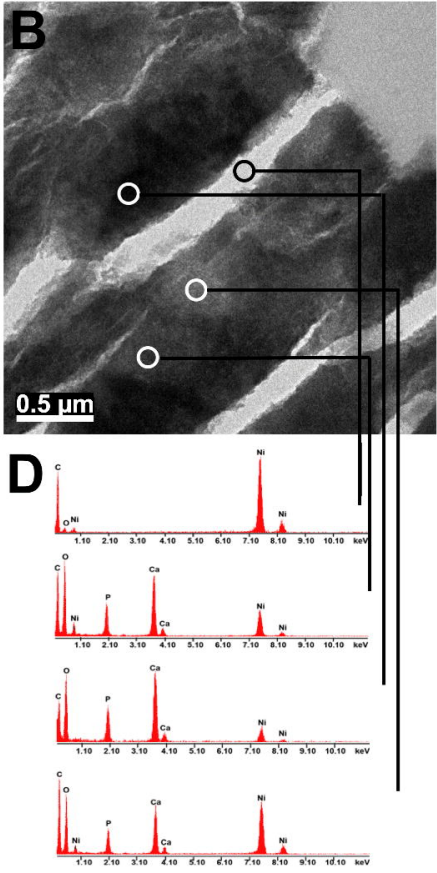


CD31 OPN

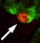

+

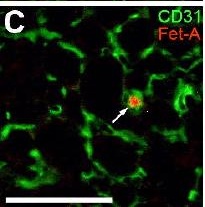

담

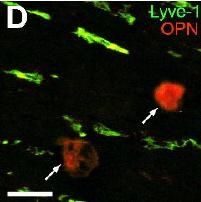




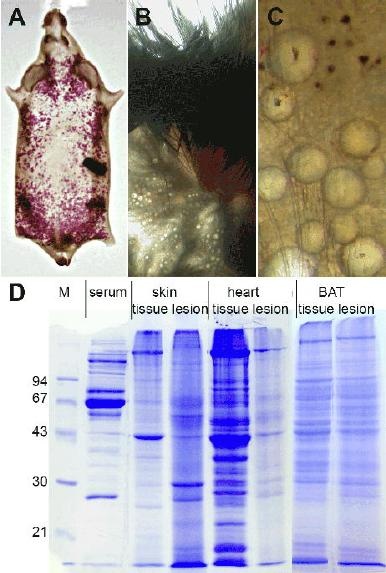




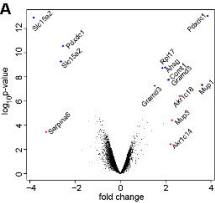

B

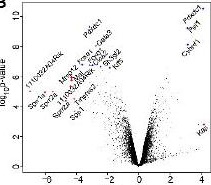

fold charge 